Supporting Information

\title{
Induction of a Heterochiral Helix through the Covalent Chiral Domino Effect Originating in the "Schellman-Motif"
}

\author{
Naoki OUSAKA and Yoshihito INAI* \\ Department of Environmental Technology and Urban Planning, Shikumi College, Graduate School \\ of Engineering, Nagoya Institute of Technology, Gokiso-cho, Showa-ku, Nagoya 466-8555, Japan \\ *Correspondence to Y. Inai (inai.yoshihito@nitech.ac.jp)
}

CONTENTS

Pages

$\begin{array}{ll}\text { - Synthesis and Characterization } & \text { S2 }\end{array}$

$\begin{array}{ll}\text { - Spectroscopic Measurements } & \text { S4 }\end{array}$

-Additional Spectroscopic Data $\quad$ S5

- Simulation of Heterochiral and Homochiral Helices for Peptide NP S10

(1) Energy Minimization by Semiempirical MO Method and Single-Point S10 DFT Computation

(2) Additional Theoretical Information of the Boundary Structure in S12 Heterochiral Helix

- Validity of Heterochiral Helix Proposed $\quad$ S16

- Simulation of Heterochiral and Homochiral Helices for Peptides N4 and N5 S17

- Theoretical Estimation of Solvent Effect on Heterochiral Helix S21

$\begin{array}{ll}\text { - References and Notes } & \text { S24 }\end{array}$ 
Synthesis and Characterization. Synthetic route of peptide N1 was based on ref $6 \mathrm{~g}$. Boc-(Aib- $\left.\Delta^{Z} \mathrm{Phe}\right)_{4}$-Aib-OMe was prepared through chain elongation by ring-opening reaction of Boc-Aib- $\Delta$ Phe azlactone with $\mathrm{H}-\left(\mathrm{Aib}-\Delta^{\mathrm{Z}} \mathrm{Phe}\right)_{\mathrm{k}}$-Aib-OMe. ${ }^{6 \mathrm{~g}, 10}$ A similar procedure via ring-opening of azlactone has been commonly performed for the preparation of $\Delta^{Z}$ Phe-containing peptides. ${ }^{\mathrm{S} 1}$ Deprotection of Boc-(Aib- $\left.\Delta^{Z} \mathrm{Phe}\right)_{4}-\mathrm{Aib}-\mathrm{OMe}$ with trifluoroacetic acid and subsequent neutralization afforded H-(Aib- $\left.\Delta^{\mathrm{Z}} \mathrm{Phe}\right)_{4}$-Aib-OMe. ${ }^{6, \mathrm{~S} 2}$ Peptide N1 was prepared by coupling of the N-free peptide and Boc-Leu-OH with N,N'-dicyclohexylcarbodiimide (DCC)/1-hydroxybenzotriazole (HOBt) system. ${ }^{\mathrm{S} 2}$ It was purified from crystallization in a mixed solvent of chloroform/methanol/hexane.

Boc group of peptide $\mathbf{N 1}$ was removed in formic acid, ${ }^{\mathrm{S} 2 \mathrm{a}, \mathrm{S} 3}$ then neutralized to yield N-terminal-free peptide H-Leu-(Aib- $\left.\Delta^{\mathrm{Z}} \mathrm{Phe}\right)_{4}$-Aib-OMe. Peptides N2-N5 were prepared by coupling of Boc-Leu-OH and H-Leu $m^{-}\left(\text {Aib- } \Delta^{Z} \text { Phe }\right)_{4}$-Aib-OMe $(m=2$ to 4$)$ with DCC/HOBt system $(m=1$ and 2) or 1-ethyl-3-(3-dimethylaminopropyl)carbodiimide hydrochloride/HOBt system ( $m=3$ and 4). ${ }^{\text {S2 }}$ Silica-gel column in ethyl acetate was used for purification of the final compounds N2-N5 (other solvents were chosen in the sample injection: chloroform/methanol, ethyl acetate/chloroform, or chloroform). Further purification was carried out for $\mathbf{N 3}$ through size-exclusion column chromatography in N,N-dimethylformamide (DMF).

Each melting point (uncorrected) might suggest temperature for decomposition. Thin-layer chromatography was carried out on pre-coated silica plates in the following solvent: (A) ethyl acetate, (B) methanol, (C) chloroform-methanol (9:1). Each mass spectrum is shown in Figure S1. The following mass calculated for $[\mathrm{M}+\mathrm{Na}]^{+}$of $\mathbf{N 1 - N 5}$ corresponds to monoisotropic value. ${ }^{\mathrm{S} 4}$ One-dimensional ${ }^{1}$ H NMR spectra of N1-N5 are displayed in Figure S2. Characterization data of peptide $\mathbf{N 1}$ were updated from ref $6 \mathrm{~g}$ as follows.

Boc-L-Leu-(Aib- $\Delta{ }^{\mathrm{Z}}$ Phe) ${ }_{4}$-Aib-OMe (N1). $\quad m p=192-193{ }^{\circ} \mathrm{C} . \mathrm{R}_{\mathrm{f}} \mathrm{A}=0.7_{4} ; \mathrm{R}_{\mathrm{f}} \mathrm{B}=0.9_{1} ; \mathrm{R}_{\mathrm{f}} \mathrm{C}=0.5_{8}$. $600 \mathrm{MHz}{ }^{1} \mathrm{H}-\mathrm{NMR}$ [ppm, in $\left.\mathrm{CDCl}_{3} /\left(\mathrm{CD}_{3}\right)_{2} \mathrm{SO}(96 / 4, \mathrm{v} / \mathrm{v} \%)\right]: 9.15$ (s, NH $\left.\Delta^{\mathrm{Z}} \mathrm{Phe}\right), 9.09$ (s, NH $\Delta^{\mathrm{Z}} \mathrm{Phe}$ ), $8.8_{2}$ (bs, NH $\Delta^{\mathrm{Z}} \mathrm{Phe}$ ), 8.80 (s, NH $\Delta^{\mathrm{Z}} \mathrm{Phe}$ ), 8.27 (s, NH Aib), 8.25 (s, NH Aib), 8.15 (bs, 2NH Aib), 7.93 (s, NH Aib), 7.56-7.17 [m, ( $\mathrm{C}^{\beta} \mathrm{H}+$ phenyl H) $\left.\Delta^{\mathrm{Z}} \mathrm{Phe}\right], 5.44$ (bs, Boc-NH Leu), 3.87 (bs, $\mathrm{C}^{\alpha} \mathrm{H}$ Leu $), 3.71\left(\mathrm{~s}, \mathrm{COOCH}_{3}\right), 1.64-1.2{ }_{0}\left(\mathrm{C}^{\beta} \mathrm{H}_{2}+\mathrm{C}^{\gamma} \mathrm{H}\right.$ Leu, $\left.\mathrm{CH}_{3} \mathrm{Aib}, \mathrm{CH}_{3} \mathrm{Boc}\right), 0.96+0.94(\mathrm{~d}+\mathrm{d}$, $\mathrm{CH}_{3}$ Leu). FT-IR (cm ${ }^{-1}$, in $\mathrm{KBr}$ ): 3275, 1658, 1628, 1539 (for selected peaks). MS (MALDI-TOF) $(\mathrm{m} / \mathrm{z}),[\mathrm{M}+\mathrm{Na}]^{+}$: calcd, 1273.6; found, 1275.2 (calibrated, 1273.5).

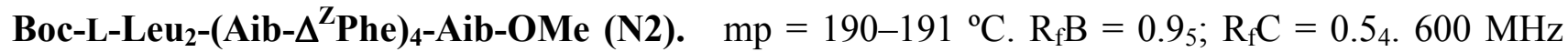
${ }^{1} \mathrm{H}-\mathrm{NMR}$ (ppm, in $\mathrm{CDCl}_{3}$ ): 9.20 (bs, NH $\Delta^{\mathrm{Z}} \mathrm{Phe}$ ), 9.13 (s, NH $\Delta^{\mathrm{Z}} \mathrm{Phe}$ ), 8.84 (bs, NH $\left.\Delta^{\mathrm{Z}} \mathrm{Phe}\right), 8.83$ (s, NH $\Delta^{Z}$ Phe), 8.27 (s, NH Aib), 8.24 (s, NH Aib), 7.94 (s, NH Aib), 7.87 (bs, NH Aib), 7.57-7.18 [m, $\left(\mathrm{C}^{\beta} \mathrm{H}+\right.$ phenyl H) $\Delta^{\mathrm{Z}} \mathrm{Phe}$, 6.58 (bs, NH Leu), 5.04 (s, Boc-NH Leu), 3.97 (bs, $\mathrm{C}^{\alpha} \mathrm{H}$ Leu), 3.71 (s, $\left.\mathrm{COOCH}_{3}\right), 3.50$ (bs, $\mathrm{C}^{\alpha} \mathrm{H}$ Leu), 1.6 ${ }_{7}-1.1_{9}\left[\left(\mathrm{C}^{\beta} \mathrm{H}_{2}+\mathrm{C}^{\gamma} \mathrm{H}\right) \mathrm{Leu}, \mathrm{CH}_{3} \mathrm{Aib}, \mathrm{CH}_{3} \mathrm{Boc}\right], 0.98+0.92(\mathrm{~d}+\mathrm{d}$, 
$\mathrm{CH}_{3} \mathrm{Leu}$ ), 0.78 (d, $\mathrm{CH}_{3}$ Leu). FT-IR ( $\mathrm{cm}^{-1}$, in KBr): 3281, 1660, 1625, 1536 (for selected peaks). MS (MALDI-TOF) (m/z), [M + Na] $]^{+}$: calcd, 1386.7; found, 1388.7 (calibrated, 1386.7).

Boc-L-Leu $\mathbf{3}_{-}\left(\mathbf{A i b}-\Delta^{\mathrm{Z}} \mathbf{P h e}\right)_{4}$-Aib-OMe (N3). $\quad \mathrm{mp}=245-246{ }^{\circ} \mathrm{C} . \mathrm{R}_{\mathrm{f}} \mathrm{A}=0.7_{6} ; \mathrm{R}_{\mathrm{f}} \mathrm{B}=0.7_{8} ; \mathrm{R}_{\mathrm{f}} \mathrm{C}=0.4_{8}$. $600 \mathrm{MHz}{ }^{1} \mathrm{H}-\mathrm{NMR}$ (ppm, in $\mathrm{CDCl}_{3}$ ): 9.22 (bs, NH $\Delta^{\mathrm{Z}} \mathrm{Phe}$ ), 9.14 (s, NH $\Delta^{\mathrm{Z}} \mathrm{Phe}$ ), 8.82 (s + bs, $2 \times \mathrm{NH}$ $\Delta^{Z}$ Phe), 8.29 (bs, NH Aib), 8.25 (s, NH Aib), 7.97 (bs, NH Aib), 7.94 (s, NH Aib), 7.58-7.18 [m, $\left(\mathrm{C}^{\beta} \mathrm{H}+\right.$ phenyl H) $\left.\Delta^{\mathrm{Z}} \mathrm{Phe}\right], 7.38$ (s, NH Leu; from proton-proton correlation), 6.55 (s, NH Leu), 5.13 (s, Boc-NH Leu), 4.01 (bs, C ${ }^{\alpha} \mathrm{H}$ Leu), 3.91 (bs, $\mathrm{C}^{\alpha} \mathrm{H} \mathrm{Leu}$ ), 3.71 (s, $\mathrm{COOCH}_{3}$ ), 3.66 (bs, $\mathrm{C}^{\alpha} \mathrm{H} \mathrm{Leu}$ ), 1.73-1.2 $\left[\left(\mathrm{C}^{\beta} \mathrm{H}_{2}+\mathrm{C}^{\gamma} \mathrm{H}\right)\right.$ Leu, $\mathrm{CH}_{3} \mathrm{Aib}, \mathrm{CH}_{3}$ Boc], 1.00-0.79 (m, $\left.\mathrm{CH}_{3} \mathrm{Leu}\right)$. FT-IR ( $\mathrm{cm}^{-1}$, in $\left.\mathrm{KBr}\right)$ : 3275, 1659, 1624, 1535 (for selected peaks). MS (MALDI-TOF) (m/z), [M + Na $]^{+}$: calcd, 1499.8; found, 1501.8 (calibrated, 1499.6).

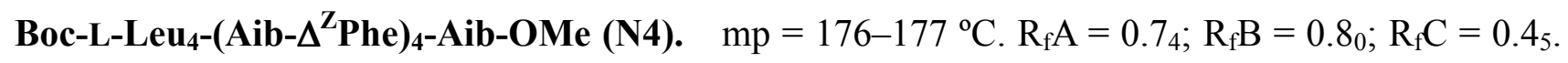
$600 \mathrm{MHz}{ }^{1} \mathrm{H}-\mathrm{NMR}$ (ppm, in $\mathrm{CDCl}_{3}$ ): 9.22 (bs, NH $\left.\Delta^{\mathrm{Z}} \mathrm{Phe}\right), 9.16$ (s, NH $\Delta^{Z} \mathrm{Phe}$ ), 8.91 (bs, NH $\Delta^{Z} \mathrm{Phe),}$ 8.84 (s, NH $\Delta^{\mathrm{Z}} \mathrm{Phe}$ ), 8.33 (bs, NH Aib), 8.26 (s, NH Aib), 8.00 (bs, NH Aib), 7.96 (s, NH Aib), 7.57-7.18 $\left[\mathrm{m},\left(\mathrm{C}^{\beta} \mathrm{H}+\right.\right.$ phenyl $\left.\left.\mathrm{H}\right) \Delta^{\mathrm{Z}} \mathrm{Phe}\right], 7.49+7.21(\mathrm{NH}$ Leu $+\mathrm{NH}$ Leu; from proton-proton correlation), 6.74 (bs, NH Leu), 5.23 (bs, Boc-NH Leu), 4.08 (bs, $\mathrm{C}^{\alpha} \mathrm{H}$ Leu), 3.96 (bs, C ${ }^{\alpha} \mathrm{H} \mathrm{Leu}$ ), 3.83 (bs, $\mathrm{C}^{\alpha} \mathrm{H} \mathrm{Leu}$ ), 3.78 (bs, $\mathrm{C}^{\alpha} \mathrm{H} \mathrm{Leu}$ ), 3.71 (s, $\left.\mathrm{COOCH}_{3}\right), 1.7_{2}-1.2_{0}\left[\left(\mathrm{C}^{\beta} \mathrm{H}_{2}+\mathrm{C}^{\gamma} \mathrm{H}\right) \mathrm{Leu}, \mathrm{CH}_{3} \mathrm{Aib}\right.$, $\mathrm{CH}_{3}$ Boc], 1.01-0.72 ( $\left.\mathrm{CH}_{3} \mathrm{Leu}\right)$. FT-IR ( $\mathrm{cm}^{-1}$, in $\mathrm{KBr}$ ): 3284, 1662, 1626, 1535 (for selected peaks). MS (MALDI-TOF) (m/z), [M + Na $]^{+}$: calcd, 1612.9; found, 1615.3 (calibrated, 1612.9).

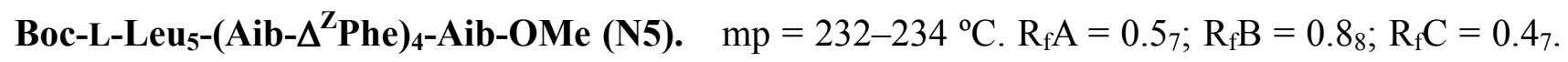
$600 \mathrm{MHz}{ }^{1} \mathrm{H}$ NMR (ppm, in $\mathrm{CDCl}_{3}$ at $298 \mathrm{~K}$ ): 9.23 (bs, NH $\Delta^{\mathrm{Z}} \mathrm{Phe}$ ), 9.15 (s, NH $\Delta^{\mathrm{Z}} \mathrm{Phe}$ ), 8.90 (bs, NH $\Delta^{Z}$ Phe), 8.82 (s, NH $\Delta^{Z}$ Phe), 8.33 (s, NH Aib), 8.25 (s, NH Aib), 8.03 (bs, NH Aib), 7.95 (s, NH Aib), 7.56-7.18 $\left[\mathrm{m},\left(\mathrm{C}^{\beta} \mathrm{H}+\right.\right.$ phenyl $\left.\mathrm{H}\right) \Delta^{\mathrm{Z}} \mathrm{Phe} ; 3 \times \mathrm{NH}$ Leu suggested from proton-proton correlation at 293 K), 6.76 (bs, NH Leu), 5.24 (bs, Boc-NH Leu), 4.07-3.76 (bs, C ${ }^{\alpha} \mathrm{H}$ Leu), 3.71 (s, $\mathrm{COOCH}_{3}$ ), 1.76-1.2 $\left[\left(\mathrm{C}^{\beta} \mathrm{H}_{2}+\mathrm{C}^{\gamma} \mathrm{H}\right)\right.$ Leu, $\left.\mathrm{CH}_{3} \mathrm{Aib}, \mathrm{CH}_{3} \mathrm{Boc}\right], 1.0-0.74$ (m, $\left.\mathrm{CH}_{3} \mathrm{Leu}\right)$. FT-IR ( $\mathrm{cm}^{-1}$, in $\left.\mathrm{KBr}\right)$ : 3285, 1659, 1626, 1536 (for selected peaks). MS (MALDI-TOF) (m/z), [M + Na $]^{+}$: calcd, 1726.0; found, 1728.5 (calibrated, 1726.3).

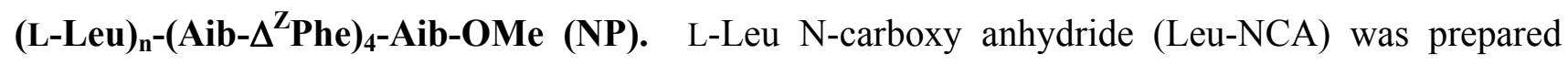
from Boc-L-amino acid essentially according to ref S5. [The procedure in ref S5 gave a small amount of triethylamine hydrochloride (TEA $\mathrm{HCl}$ ) as a contamination of NCA. In the present case, TEA HCl content was ca. $1.2-1.3 \mathrm{~mol} \%$ for NCA.] H-L-Leu $5-\left(\text { Aib- } \Delta^{Z} \text { Phe }\right)_{4}$-Aib-OMe $(25 \mathrm{mg}, 16 \mu \mathrm{mol})$ as initiator, ${ }^{\mathrm{S} 6}$ prepared from Boc-deprotection of N5, was dissolved in DMF $(100 \mu \mathrm{L})$, while the Leu-NCA (48-49 mg, $0.31 \mathrm{mmol})$ was dissolved in DMF $(150 \mu \mathrm{L})$. The initiator solution was added to the NCA solution at room temperature. The reaction mixture stood for ca. $24.5 \mathrm{~h}$ at room temperature. After the highly-viscous mixture was diluted with DMF/chloroform, it was purified 
through size-exclusion column chromatography in DMF to obtain peptide NP: Yield, $41 \mathrm{mg}$.

Its molecular weight was evaluated from the MALDI-TOF mass analysis on peptide NP via $\mathrm{N}$-acetyl-protection: peptide NP was dissolved in acetic anhydride/dichloromethane (1/1, v/v \%), and stood at room temperature for ca. $18 \mathrm{~h}$. After removal of the solvent, the remaining solid was subjected to the mass spectroscopy. The mass profile of peptide NP (Figure S1A, NP) yielded a somewhat complicated pattern suggesting various fragmentations. On the other hand, the pattern was relatively simplified in NP treated with acetic anhydride (Figure S1B, NP). Major peaks at each of the sequential signals were usually ascribed to acetylated peptides NP with different numbers of Leu residue. The average molecular weight of NP was calculated from position and intensity of the sequential peaks picked up as acetylated peptide NP $\left([\mathrm{M}+\mathrm{Na}]^{+}\right): M_{\mathrm{n}}($ calibrated $)=3852$ (number of Leu $\sim 24) ; M_{\mathrm{w}} / M_{\mathrm{n}}=1.03$

Spectroscopic Measurements. Spectroscopic procedures were done basically according to refs 6f,S7. ${ }^{1} \mathrm{H} \mathrm{NMR}$ data were acquired in $\mathrm{CDCl}_{3}$ or $\mathrm{CDCl}_{3} /\left(\mathrm{CD}_{3}\right)_{2} \mathrm{SO}$ on Bruker spectrometers [DRX-600 (600 MHz) or DPX-200 (200 MHz); Bruker BioSpin: Karlsruhe, Germany; Tsukuba, Japan]. NOESY spectra were obtained on the Bruker DRX-600 using the Bruker pulse program ("noesytp" ${ }^{\mathrm{S} 8}$ ) usually with a mixing time of $200 \mathrm{~ms}, 4$ scans, $2 \mathrm{~K}$ data points in $\mathrm{F} 2$, and 256 points in F1. Proton-proton correlation was investigated with the Bruker pulse program ("mlevtp" ${ }^{\mathrm{S} 9}$ ). Processing and analysis of NMR data were done with the Bruker-XWINNMR software (ver 2.5) or SPINWORKS. ${ }^{\mathrm{S} 10}$ (For comprehensive NMR guidelines for biopolymers, ref S11; for NMR data of analogous nonapeptides, see refs $6 \mathrm{e}, \mathrm{f}, \mathrm{g}, 10, \mathrm{~S} 7$.) FT-IR spectra were obtained at ambient temperature on a JASCO FT/IR-430 spectrometer in $\mathrm{KBr}$ or in solution.

$\mathrm{CD}$ and UV absorption data were obtained at ambient temperature for peptide solutions (usually at $1.0 \times 10^{-5}-1.6 \times 10^{-5} \mathrm{M}$ ) on a JASCO J-820 spectrometer. Solvents expect for 2,2,2-trifluoroethanol were distilled over $\mathrm{CaSO}_{4}$. The peptide concentration was determined on the basis of $\varepsilon$ (maximum around $280 \mathrm{~nm}$ for per $\Delta^{\mathrm{Z}} \mathrm{Phe}$ residue) $=1.8 \times 10^{4}{ }^{6 \mathrm{f}}$ (Similar $\varepsilon$ values were reported in refs $\mathrm{S} 12, \mathrm{~S} 13$.) The same $\varepsilon$ value was assumed in all solvents used here for comparison of $\mathrm{CD}$ intensity. The ordinate $\varepsilon$ and $\Delta \varepsilon$ values in all spectral data were expressed per $\Delta^{\mathrm{Z}} \mathrm{Phe}$ concentrations. ( $\varepsilon$ and $\Delta \varepsilon$ of peptide concentration are obtained from multiplication of the $\Delta^{\mathrm{Z}}$ Phe-based $\varepsilon$ and $\Delta \varepsilon$ by four.) Mathematical smoothing of CD spectra was done to reduce their noise.

MALDI-TOF mass spectra of all peptides were obtained on PerSpective Biosystems Voyager-DE $^{\mathrm{TM}}$ RP [Applied Biosystems (changed from PerSeptive Biosystems); Foster City CA; Tokyo, Japan] in reflectron mode, using 1,8,9-anthracenetriol matrix and NaI salt to prepare the

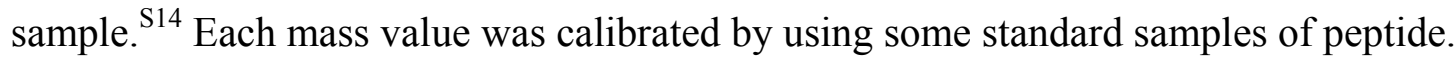


Additional Spectroscopic Data. FT-IR spectra of N1-N5 in solution (Figures S3A,B and Table S1) yielded a similar amide I pattern that is mainly characterized by two absorption bands. The former band around $1660 \mathrm{~cm}^{-1}$ should be assigned to saturated amino acids incorporated into a helix, whereas the latter around $1627 \mathrm{~cm}^{-1}$ should be based on $\Delta^{Z}$ Phe residues in a helical form. ${ }^{S 15}$ A similar spectral pattern was often observed for a helical conformation of oligopeptides based on -(Aib- $\left.\Delta^{\mathrm{Z}} \mathrm{Phe}\right)-$ or $-\left(\Delta^{\mathrm{Z}} \mathrm{Phe}-\mathrm{Aib}\right)-$ units. ${ }^{6 e, \mathrm{f}, 10, \mathrm{~S} 7, \mathrm{~S} 16}$ Solvent dependence of NH chemical shifts in $\mathrm{CDCl}_{3}$ (Figure S4) indicated that most NH's are essentially insensitive to the addition of hydrogen-accepting $\left(\mathrm{CD}_{3}\right)_{2} \mathrm{SO},{ }^{\mathrm{S} 17-\mathrm{S} 19}$ which markedly influences two NH's, that is, N-terminal urethane NH and another amide NH. The lack of two intramolecular hydrogen-bonding NH's at least implies the presence of 310 -helical conformation ${ }^{\mathrm{S} 20}$ in these peptides. Such a 310 -helix was also found in analogous peptides in solution and in the crystal states. ${ }^{6 e, f, 10, \mathrm{~S} 7}$ Strong propensity to helical structures has been widely demonstrated through conformational studies of Aib- or $\Delta^{\mathrm{Z}}$ Phe-peptides. ${ }^{\text {S21-S23 }}$

CD data around $280 \mathrm{~nm}$ of peptides N1-NP in several solvents are summarized in Figures S5 and S6. Split-CD signs around $280 \mathrm{~nm}$ were assigned to a helical screw sense according to refs 6e,f,S7,S24,S25.

Peptide NP showed an amide I absorption band (Figure S3C and Table S1) that should be assigned to an $\alpha$-helical conformation in the Leu-segment. ${ }^{\text {S26 }}$ The occurrence of $\alpha$-helix was also supported from electronic CD pattern ${ }^{13}$ of NP (Figure 2B and Figure S7B) in 2,2,2-trifluoroethanol. The CD spectra of peptide NP were essentially similar to each other in a concentration range (Figure S7B), implying that some self-aggregation is unimportant in our present observations. In chloroform (Figure S7A), some concentration dependence of CD amplitude was seen. However, our conclusions are not substantially influenced, judging from the CD amplitude range of NP (black bar) shown in Figure S6 in chloroform. 

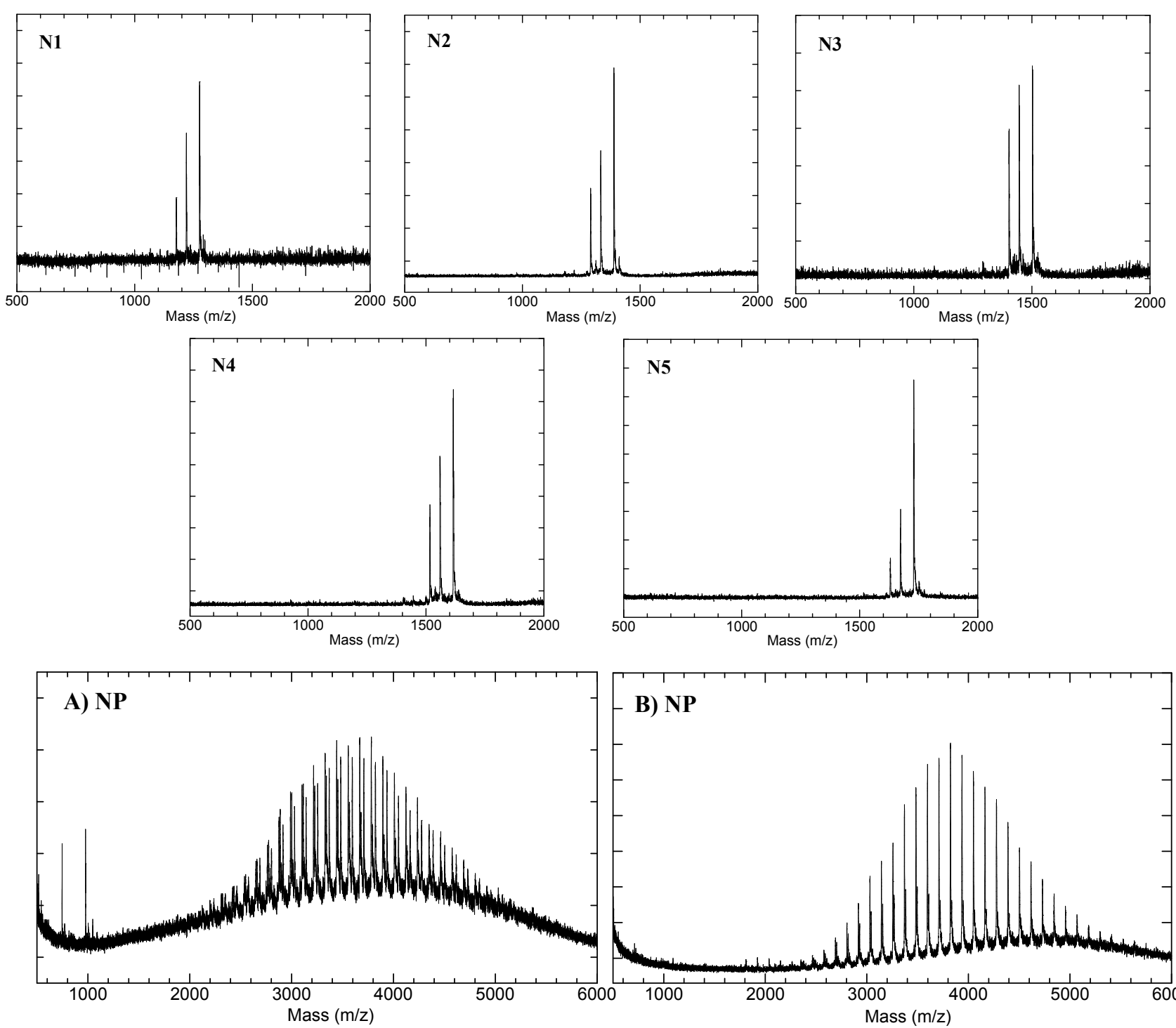

B) NP

Figure S1. MALDI-TOF mass spectra of peptides N1-NP. The mass scale in each abscissa is not corrected. In addition to $[\mathrm{M}+\mathrm{Na}]^{+}$, two prominent peaks at lower mass are seen in Boc-protected peptides N1-N5, suggesting fragmentations of $t$-butyl and Boc moieties. (A) and (B) stand for NP and NP treated with acetic anhydride, respectively: for the details, see the text. 


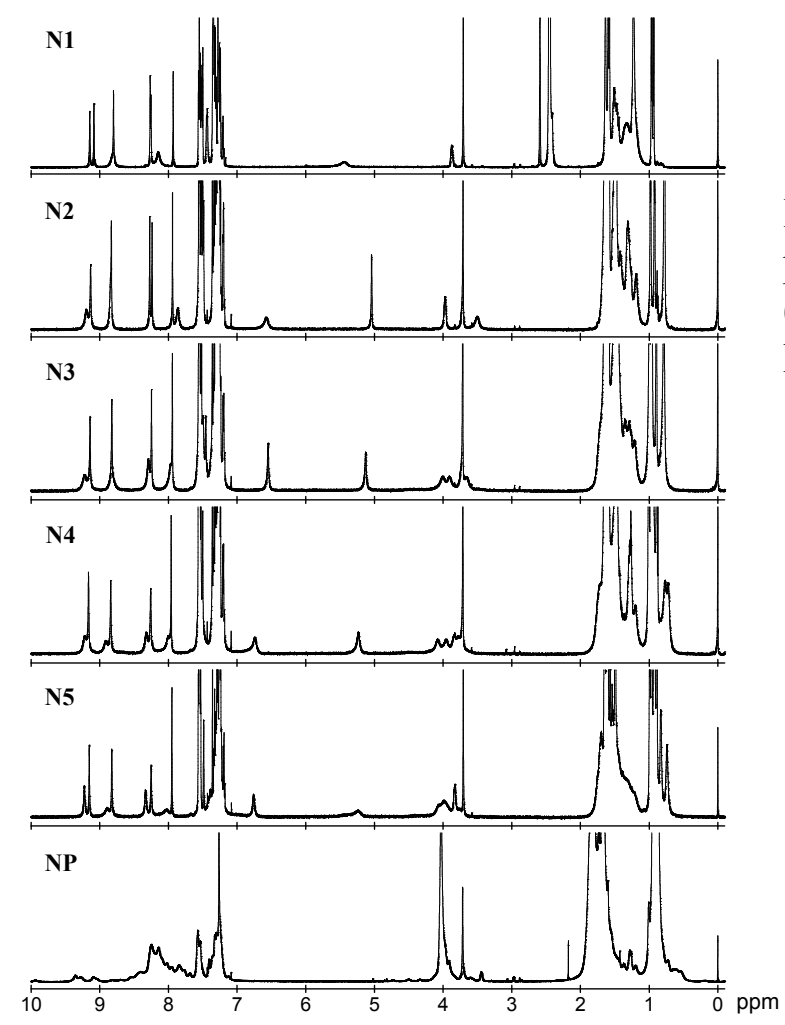

Figure S2. $600 \mathrm{MHz}-{ }^{1} \mathrm{H}$ NMR spectra of peptides $\mathbf{N 1}-\mathbf{N P}$ in $\mathrm{CDCl}_{3}\left[\mathrm{CDCl}_{3} /\left(\mathrm{CD}_{3}\right)_{2} \mathrm{SO}\right.$ $(96 / 4, \mathrm{v} / \mathrm{v} \%)$ for $\mathrm{N1}]$ at $293 \mathrm{~K}(298 \mathrm{~K}$ for N5): $[\mathbf{N 1}-\mathbf{N 5}]=3 \mathrm{mM} ;[\mathbf{N P}]=8 \mathrm{mg} / \mathrm{mL}$.
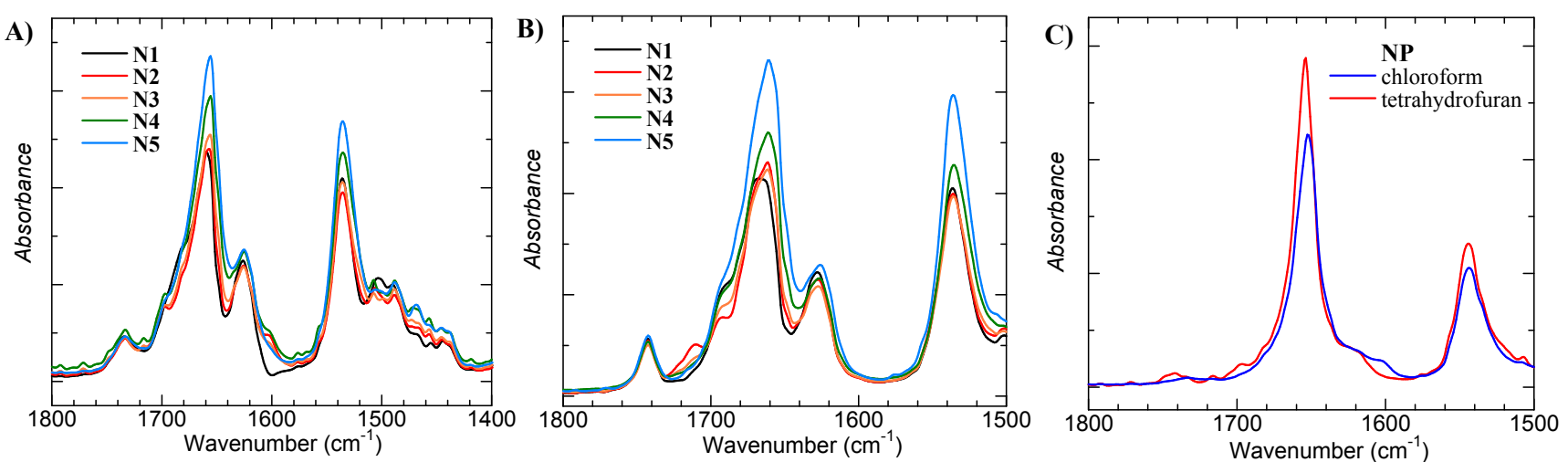

Figure S3. Expanded FT-IR spectra of peptides N1-N5 in (A) chloroform and (B) tetrahydrofuran, and (C) NP in the two solvents at ambient temperature.

Table S1. Major peak positions ${ }^{\mathrm{a}}$ for amide I and II

\begin{tabular}{|c|c|c|c|c|c|c|}
\hline \multirow{2}{*}{} & \multicolumn{3}{|c|}{ chloroform } & \multicolumn{3}{c|}{ tetrahydrofuran } \\
\cline { 2 - 7 } & \multicolumn{2}{|c|}{ amide I } & amide II & \multicolumn{2}{c|}{ amide I } & amide II \\
\hline N1 & 1659 & 1627 & 1536 & 1663 & 1628 & 1536 \\
\hline $\mathbf{N 2}$ & 1657 & 1626 & 1536 & 1661 & 1628 & 1536 \\
\hline $\mathbf{N 3}$ & 1656 & 1625 & 1536 & 1661 & 1628 & 1536 \\
\hline N4 & 1656 & 1625 & 1535 & 1661 & 1627 & 1536 \\
\hline N5 & 1656 & 1625 & 1535 & 1661 & 1626 & 1536 \\
\hline NP & 1653 & & 1544 & 1654 & & 1545 \\
\hline
\end{tabular}

${ }^{\mathrm{a}}$ in $\mathrm{cm}^{-1}$, obtained from Figure S3. 

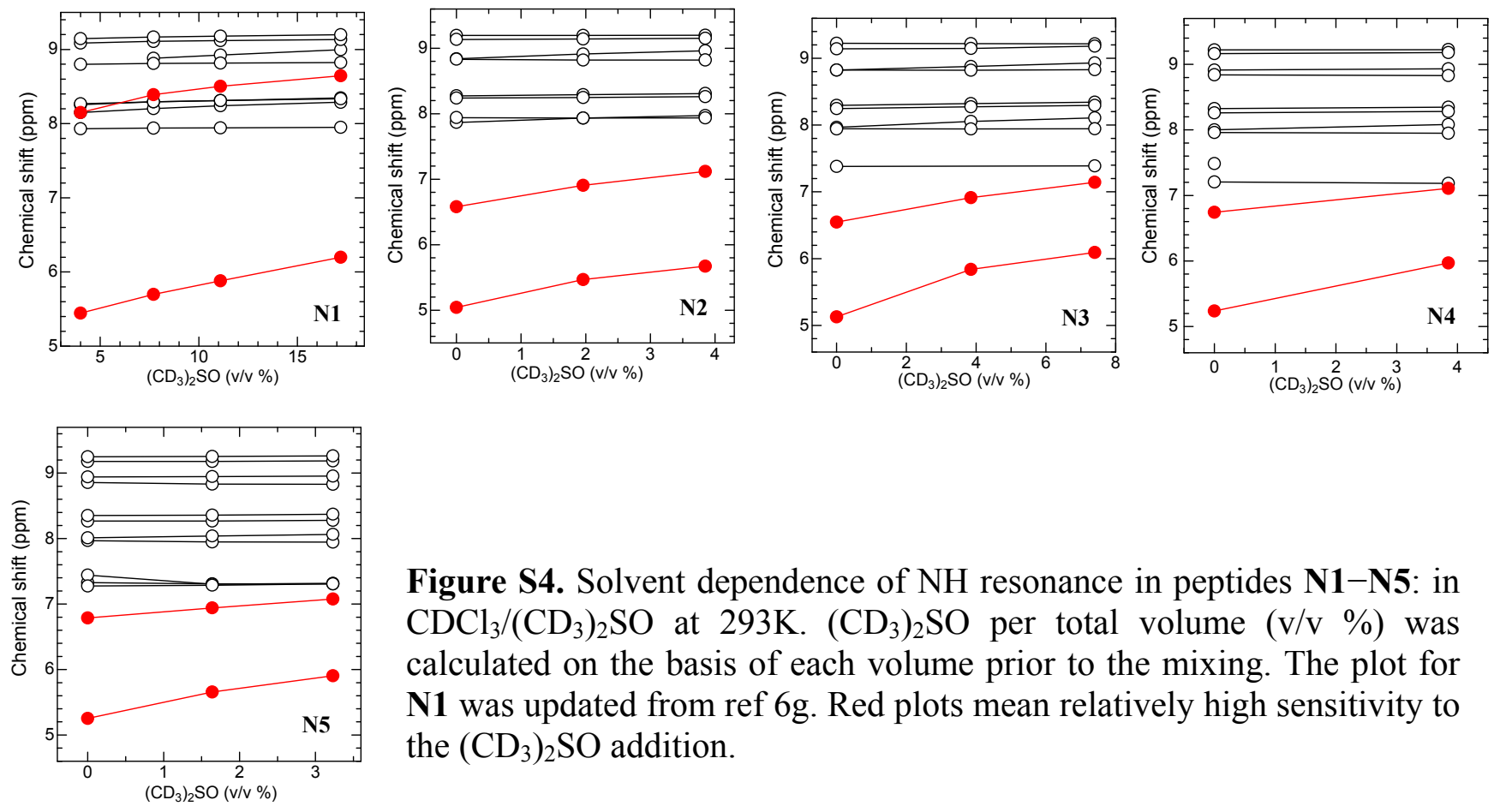

Figure S4. Solvent dependence of NH resonance in peptides N1-N5: in $\mathrm{CDCl}_{3} /\left(\mathrm{CD}_{3}\right)_{2} \mathrm{SO}$ at $293 \mathrm{~K}$. $\left(\mathrm{CD}_{3}\right)_{2} \mathrm{SO}$ per total volume (v/v \%) was calculated on the basis of each volume prior to the mixing. The plot for N1 was updated from ref $6 \mathrm{~g}$. Red plots mean relatively high sensitivity to the $\left(\mathrm{CD}_{3}\right)_{2} \mathrm{SO}$ addition.
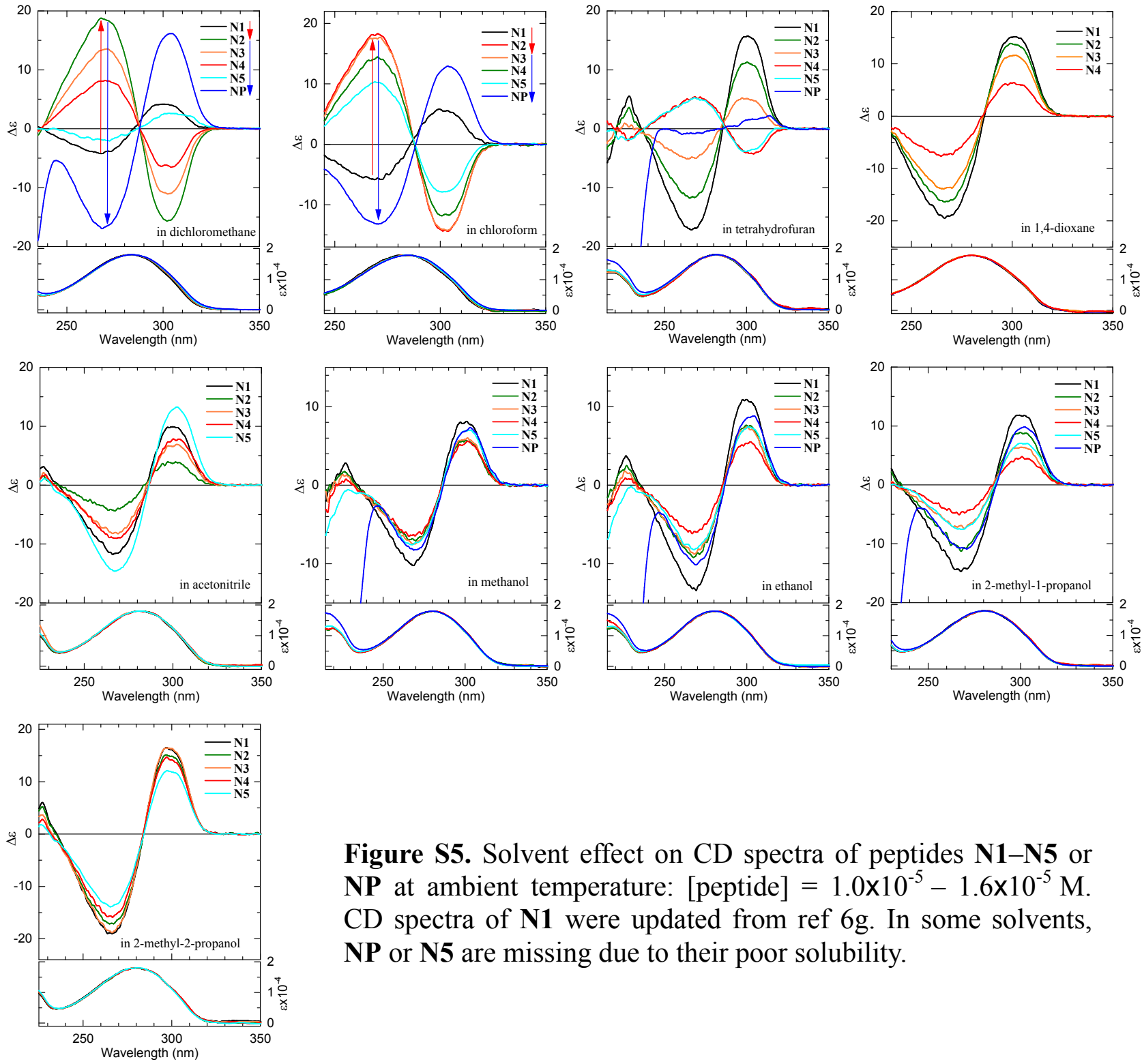

Figure S5. Solvent effect on CD spectra of peptides N1-N5 or NP at ambient temperature: [peptide] $=1.0 \times 10^{-5}-1.6 \times 10^{-5} \mathrm{M}$. $\mathrm{CD}$ spectra of $\mathbf{N 1}$ were updated from ref $6 \mathrm{~g}$. In some solvents, NP or N5 are missing due to their poor solubility. 


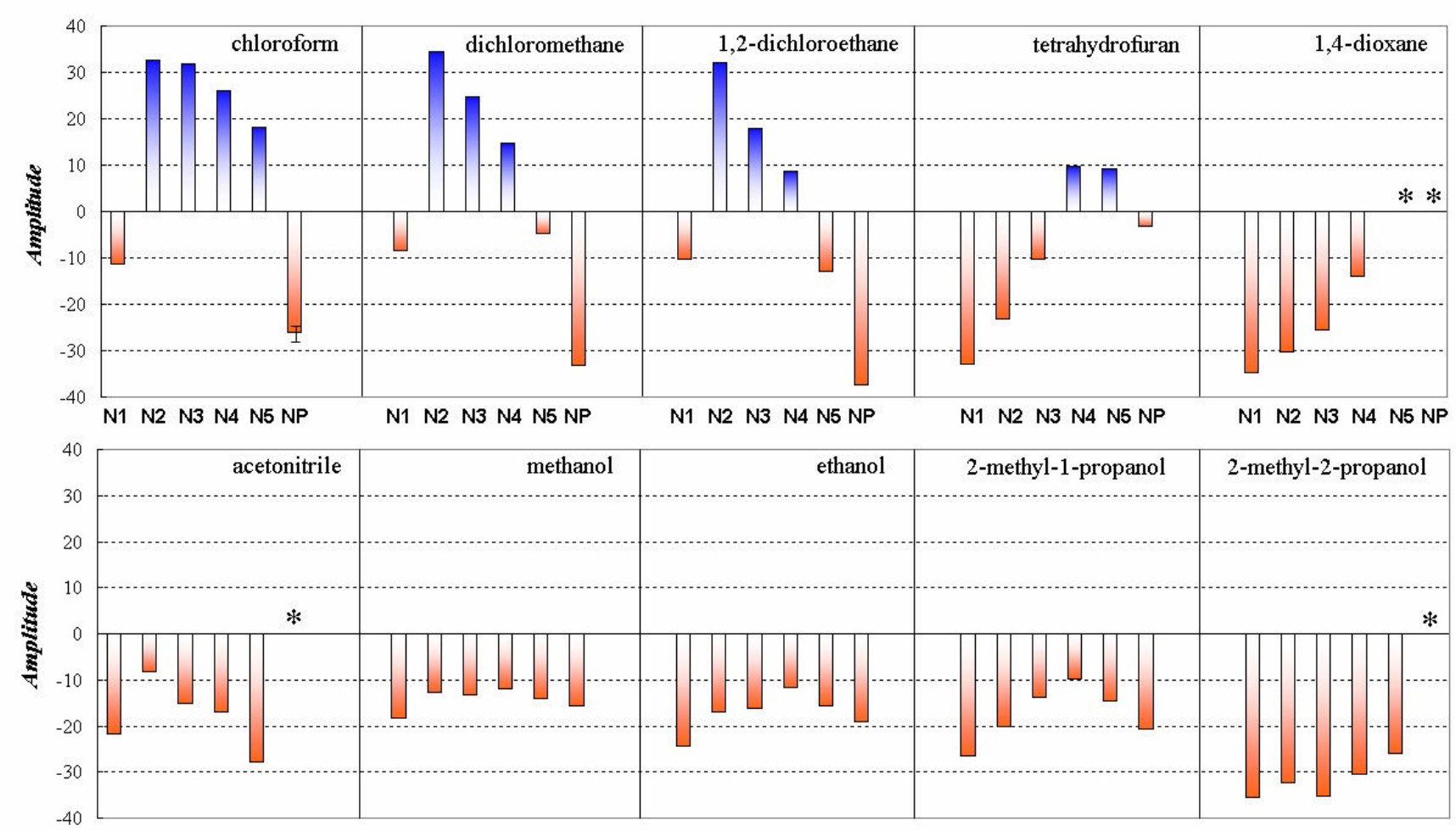

Figure S6. Summary of CD amplitude of peptides N1-NP in each solvent: obtained from Figures 2 and S5. The ordinate is defined by amplitude of split-type CD profile of $\Delta^{Z}$ Phe residue (around 280 $\mathrm{nm}$ ): its negative sign corresponds to left-handed helix sense (split CD of a positive peak at long wavelengths). ${ }^{\text {S27 }}$ Asterisk indicates missing data due to their poor solubility. As for NP in chloroform $\left([\mathbf{N P}]=1.3 \times 10^{-5} \mathrm{M}\right)$, the black bar is superimposed on the data of NP. It means a range in CD amplitudes at higher and lower concentrations $\left([\mathbf{N P}]=1.3 \times 10^{-4}\right.$ and $4.0 \times 10^{-6} \mathrm{M}$ : see Figure S7 and its caption).
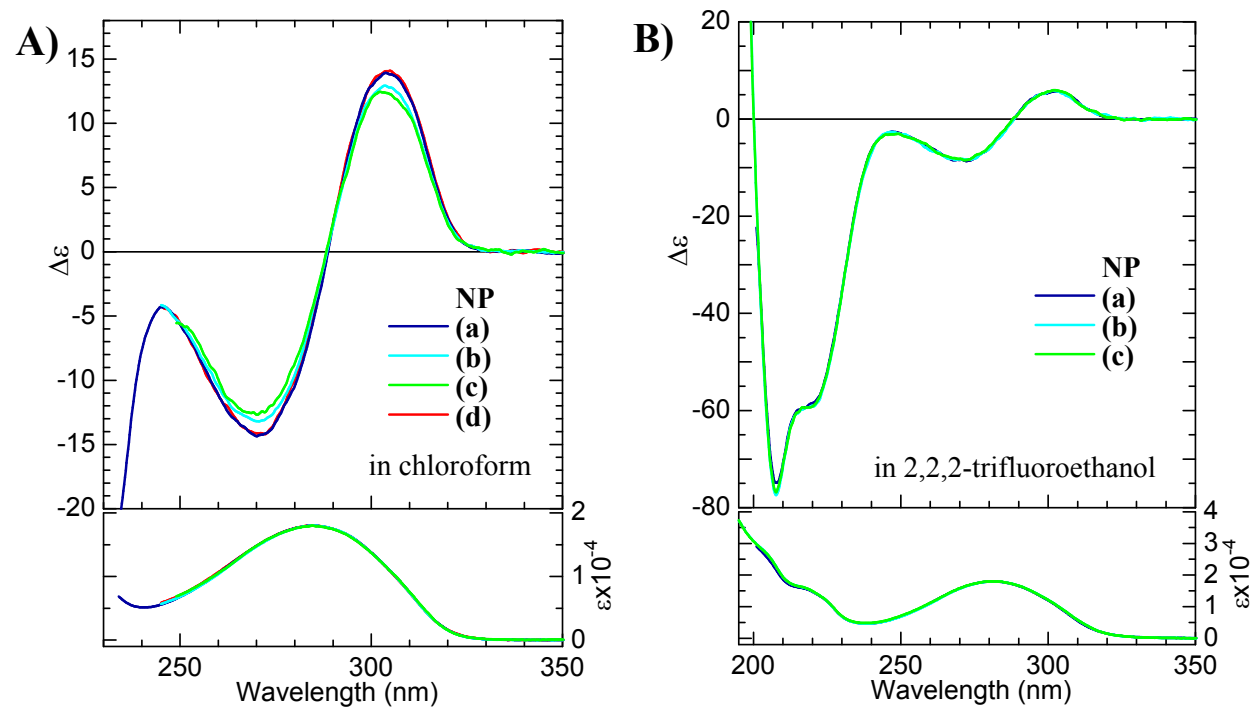

Figure S7. CD spectra of peptide NP in (A) chloroform and (B) 2,2,2-trifluoroethanol at different peptide concentrations (M): in (A), (a) $1.3 \times 10^{-4}$, (b) $1.3 \times 10^{-5}$, and (c) $4.0 \times 10^{-6}$; in (B), (a) $1.4 \times 10^{-4}$, (b) $6.3 \times 10^{-6}$, and (c) $3.0 \times 10^{-6}$. In (A), NP treated with acetic anhydride is also provided as spectrum (d) at $1.3 \times 10^{-5} \mathrm{M}$. Figure S7A(b) was obtained from the same data as Figure S5 of NP in chloroform. Likewise, Figure S7B(b) was obtained from Figure 2B of NP in 2,2,2-trifluoroethanol. 


\section{Simulation of Heterochiral and Homochiral Helices for Peptide NP}

\section{(1) Energy Minimization by Semiempirical MO Method and Single-Point DFT Computation.}

Semiempirical molecular orbital (MO) calculation was carried out to predict heterochiral or homochiral helical structures in peptide NP. Here the L-Leu residue was replaced by L-Ala residue to reduce conformational freedom in the Leu side chain. ${ }^{2}$ The 20 -mer fragment of L-Ala, Ac-L-Ala $20^{-}$ (L-20: Ac, acetyl), was used for the L-sequence, while the achiral sequence, -(Aib- $\left.\Delta{ }^{\mathrm{Z}} \mathrm{Phe}\right)_{4}-\mathrm{Aib}-\mathrm{OMe}$ (A-9), was used without modification. CD pattern of NP displayed in Figure 2B indicated a typical right-handed $\alpha$-helix in the L-Leu sequence. Thus the L-20 adopted a right-handed $\alpha$-helix $(\phi, \psi)=$ $\left(-57^{\circ},-47^{\circ}\right),{ }^{\mathrm{S} 28}$ or additionally 310 -helix $\left(-60^{\circ},-30^{\circ}\right){ }^{\mathrm{S} 29}$ Peptides based on $-\left(\right.$ Aib- $\left.\Delta{ }^{\mathrm{Z}} \mathrm{Phe}\right)-$ or $-\left(\Delta^{Z}\right.$ Phe-Aib $)$ - units were found to fold into a 310 -helical structure in solution or in crystalline states. $^{6 e, f, 10, \mathrm{~S} 7, \mathrm{~S} 16}$ Correspondingly, the achiral sequence of A-9 was set to a right-handed $3{ }_{10}$-helix $\left(-60^{\circ},-30^{\circ}\right)$ or its left-handed $3_{10}$-helix $\left(+60^{\circ},+30^{\circ}\right)$.

Combinations of the above conformers yield four types of backbones $(\phi, \psi)^{\mathrm{S} 28-\mathrm{S} 30}: \mathrm{L}-20\left(-57^{\circ}\right.$, $\left.-47^{\circ}\right) /$ A-9 $\left(+60^{\circ},+30^{\circ}\right)$; L-20 $\left(-60^{\circ},-30^{\circ}\right) /$ A-9 $\left(+60^{\circ},+30^{\circ}\right)$; L-20 $\left(-57^{\circ},-47^{\circ}\right) /$ A-9 $\left(-60^{\circ},-30^{\circ}\right)$; L-20 $\left(-60^{\circ},-30^{\circ}\right) /$ A-9 $\left(-60^{\circ},-30^{\circ}\right)$. Each $\Delta^{Z}$ Phe-side chain was commonly oriented in $\chi^{2}=-40^{\circ}$ (for right-handed helix) or $+40^{\circ}$ (for left-handed helix). ${ }^{\mathrm{S} 31}$ The C-terminal Aib residue adopted the opposite helical sense, on the basis of helical reversal at C-capping motif. ${ }^{\mathrm{S} 32}$ From these starting conformers, the $\mathrm{AM} 1^{15}$-based energy minimization was carried out on Gaussian $03^{\mathrm{S} 33}$ with variables of all structural parameters.

For the four structures obtained (types I-IV), each energy and dipole moment are summarized in Table S2. The corresponding molecular structures are displayed in Figure 3 for types I-II and Figure S8 for types III-IV. (The molecular graphics for this article, including helical forms in Figure 1, were basically made with the Arguslab, ${ }^{18}$ unless noted.) The energy at the AM1 level ${ }^{15, \mathrm{~S} 33}$ was ordered in type II < type IV < type I < type III. This indicates that the homochiral type II is somewhat more stable than the heterochiral type I. However, the energy order was type II $<$ type I $<$ type IV < type III at the DFT level of B3LYP/6-31G(d,p), which will be expected to improve the accuracy. ${ }^{\mathrm{S} 33-\mathrm{S} 35}$ Notably, the energy difference in types I and II was close to each other. In types I-IV, the chiral segment of Ala(1-16) commonly adopted periodic hydrogen bonds of $(i)$ th $\mathrm{CO} \rightarrow(i+4)$ th NH type for $\alpha$-helix. ${ }^{\mathrm{S} 20, \mathrm{~S} 28}$ It also involves those of $(i)$ th $\mathrm{CO} \rightarrow(i+3)$ th $\mathrm{NH}$ type for $3{ }_{10}$-helix. ${ }^{\text {s20a }}$ The $\mathrm{O} \cdots \mathrm{H}$ distance was mostly found to be $2.1-2.3 \AA$ for the former type, while being longer (2.4-2.5 $\AA$ ) for the latter type. (For the criteria for hydrogen-bond formation, see ref S36.) Thus, the Ala-segment should adopt essentially an $\alpha$-helix. The propensity for $\alpha$ - and $33_{10}$-helices in chain length of Ala-based peptides has been theoretically demonstrated through elegant MO computations. $^{\text {S37 }}$

Heterochiral type III (Figure S8) adopted, in comparison with type I (Figure 3), a relatively 
straight form that involves a $5 \rightarrow 1$ hydrogen bond at the boundary: $\mathrm{O}$ [Ala(17) CO] $\cdots \mathrm{H}[\mathrm{Aib}(21)$ $\mathrm{NH}]=2.26 \AA$. Helix termini involving such type of hydrogen bond are defined as the " $\alpha_{L}$-motif". ${ }^{3 b, S 38}$ In contrast, the boundary sequence in the type I involves $6 \rightarrow 1$ and $5 \rightarrow 2$ hydrogen bonds, being characterized as the "Schellman-motif". ${ }^{3 \mathrm{a}-\mathrm{c}, \mathrm{aa}, \mathrm{S} 19 \mathrm{c}, \mathrm{S} 38, \mathrm{~S} 39}$ (The detailed hydrogen-bonding parameters will be shown in Table S3.)

However, the heterochiral type III should be unfavorable than the heterochiral type I from the energetic criteria, particularly at the DFT level. Thus, when the present sequence takes a heterochiral helix, it should favor the Schellman-motif-type hydrogen bonds. In the case of the homochiral helix, the type II should be energetically more favorable than the type IV.

In the stable heterochiral helix (type I) and homochiral helix (type II), their main-chain torsion angles are graphically summarized in Figure S9. The two backbones adopted almost the same $(\phi, \psi)$ in the Ala(1)-Ala(15) sequence, retaining essentially a right-handed $\alpha$-helical conformation as mentioned before. Both the C-terminal Aib(29) residues took the opposite sense to the preceding sequence, thus retaining the corresponding starting models.

In contrast, the heterochiral type I showed dramatic conformational transition at the Ala(16)-Aib(21) residues, followed by essentially a left-handed $3{ }_{10}$-helix at the Aib(21)- $\Delta^{\mathrm{Z}} \mathrm{Phe}(28)$ residues. The homochiral type II involved an essentially $\alpha$-helical conformation for L-20, and an $\alpha / 3_{10}$-mixed conformation for A-9 (for experimental example of $\alpha / 3_{10}$-helices, see ref S22e). Thus the homogeneity in the backbone was somewhat disturbed around the Ala(18)-Aib(21) residues. Whereas the A-9 sequence originally prefers $3{ }_{10}$-helix to $\alpha$-helix, ${ }^{6 \mathrm{e}-\mathrm{f}, 10, \mathrm{~S} 7}$ the preceding L-20 in a right-handed $\alpha$-helix structurally synchronizes with the N-terminal sequence of A-9. As a result, the molecular axis of type II (Figure 3) somewhat bends at the chiral/achiral boundary.

However, the heterochiral type I bends more sharply at the boundary, thus yielding a smaller dipole moment, at both the AM1 and DFT levels, than does the homochiral type II (Table S2).

Table S2. Energy and Dipole Moment for Heterochiral and Homochiral Helices Predicted ${ }^{\mathrm{a}}$

\begin{tabular}{|c|c|c|c|c|}
\hline \multirow{2}{*}{} & \multicolumn{2}{|c|}{ heterochiral helix } & \multicolumn{2}{c|}{ homochiral helix } \\
\cline { 2 - 5 } & type I & type III & type II & type IV \\
\hline energy difference $\left(\mathrm{kcal} \mathrm{mol}^{-1}\right)^{\mathrm{b}}$ & & & & \\
AM1 & +0.81 & +1.57 & 0 & +0.56 \\
DFT & +0.17 & +3.75 & 0 & +2.35 \\
\hline dipole moment (D) & & & & \\
AM1 & 100.4 & 111.1 & 113.7 & 114.0 \\
DFT & 119.4 & 131.8 & 134.9 & 135.4 \\
\hline
\end{tabular}

${ }_{\mathrm{a}}^{\mathrm{a}}$ In the DFT, single-point calculation at the B3LYP/6-31G(d,p) level ${ }^{\mathrm{S} 33-\mathrm{S} 35}$ was performed for the four structures energy-minimized from the AM1 method. ${ }^{15, \mathrm{~S} 33}$ These helical structures are shown in Figures 3 and S8. ${ }^{b}$ Energy value of type II is set to zero for the standard. 

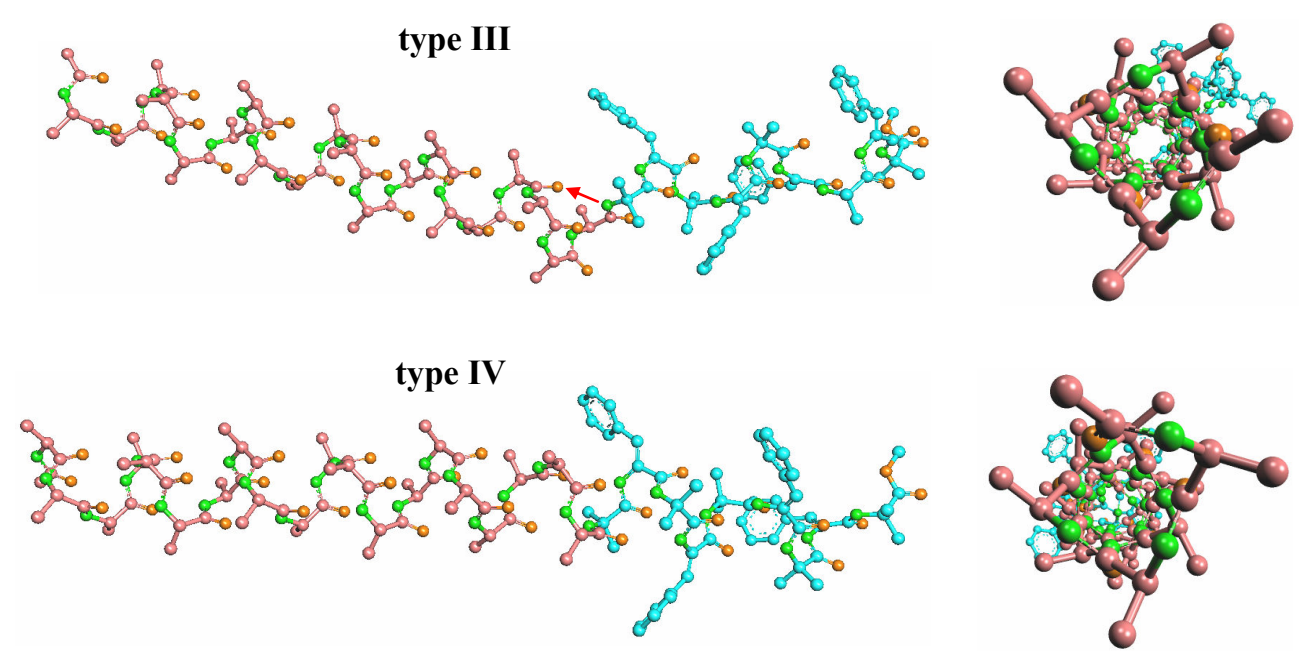

Figure S8. Another heterochiral helix (type III) and homochiral helix (type IV) theoretically simulated in Ac-L-Ala $20-\left(\text { Aib- } \Delta^{Z} \text { Phe }\right)_{4}$-Aib-OMe. In type III, the $5 \rightarrow 1$ hydrogen bond at the boundary is indicated in the red arrow.

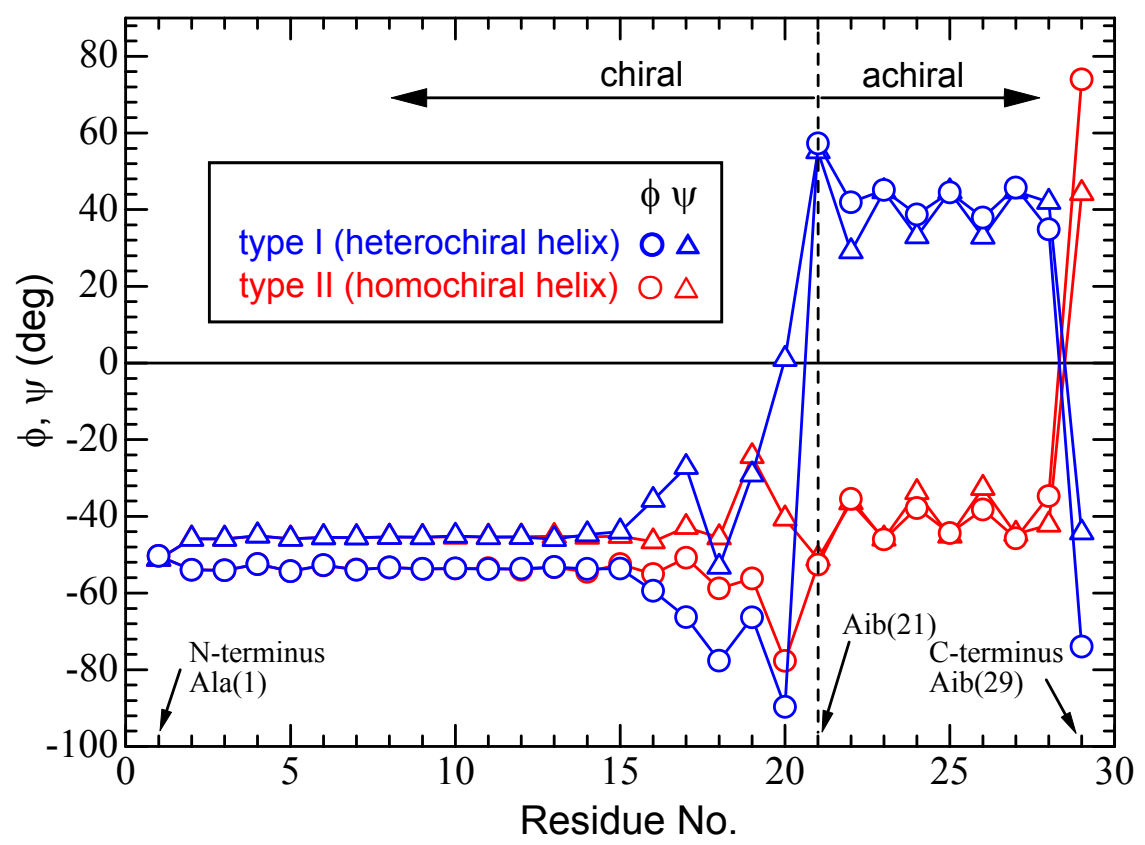

Figure S9. Main-chain torsion angles $(\phi, \psi)$ of each residue for Ac-L-Ala $20-\left(\text { Aib- } \Delta{ }^{Z} \text { Phe }\right)_{4}-A i b-O M e$ in the heterochiral helix (type I) and homochiral helix (type II): for their structures, see Figure 3.

(2) Additional Theoretical Information of the Boundary Structure in Heterochiral Helix. The Schellman motif is characterized by the proximity between 1-6 residues in a segment adopting the opposite helix sense at 5 th residue. ${ }^{3 \mathrm{a}-\mathrm{c}, \mathrm{a}, \mathrm{S} 19 \mathrm{c}, \mathrm{S} 38, \mathrm{~S} 39}$ Concomitantly, side-chain proximity between the 1-6 residues and hydrogen-bonding loop of $6 \rightarrow 1$ type (often accompanied with $5 \rightarrow 2$ type) are expected at the boundary sequence. ${ }^{3 \mathrm{a}-\mathrm{c}, 7 \mathrm{a}, \mathrm{S} 19 \mathrm{c}, \mathrm{S} 38, \mathrm{~S} 39}$ In the preceding simulation, the Ala(17) and $\Delta^{\mathrm{Z}} \mathrm{Phe}(22)$ correspond to the 1-6 relation, in which the methyl and phenyl side chains are relatively 
close to each other.

To simulate the side-chain pairs in NP, the Ala(17) in the type I (shown in Figure 3) was replaced by Leu residue to obtain Ac-L-Ala $1_{6}-\mathrm{L}-\mathrm{Leu}-\mathrm{L}-\mathrm{Ala}_{3}-\left(\mathrm{Aib}-\Delta^{\mathrm{Z}} \mathrm{Phe}\right)_{4}$-Aib-OMe. Some orientations of the Leu side chain ${ }^{2}$ were considered for initial conformations, each of which was energy-minimized at the AM1 level ${ }^{15}$ in Gaussian $03 .{ }^{\mathrm{S} 33}$ Among the energy-minimized structures, the lowest-energy one is displayed in Figure S10. It retains a bending form similar to the type I of the all-Ala chiral sequence (Figure 3: type I). Similarity was also found in the backbone torsion angles (Figure S11) and the hydrogen-bond parameters at the Schellman motif (Table S3). In both peptides, the $6 \rightarrow 1$ hydrogen bond was suggested together with the $5 \rightarrow 2$ type. Therefore, such a bending form is considered to originate from the nature of the chiral/achiral backbone.

On the other hand, the side-chain pairs at the 1-6 position were close to each other. In particular, the shortest distance between the alkyl side chain and phenyl-ring center was $3.2 \AA$ for one $\mathrm{H}^{\beta}$ of $\operatorname{Leu}(17)$ in the Leu-substituted peptide (Figure S10), and $2.9 \AA$ for one $\mathrm{H}^{\beta}$ of Ala(17) in the all-Ala chiral sequence (Figure 3: type I). This implies that some $\mathrm{CH}-\pi$ interaction $^{\mathrm{S} 40}$ at the $1-6$ pair partially contributes to stabilization of the bending form of a heterochiral helix.

To predict the boundary structure at a higher level, we performed the two-layered "ONIOM" method $^{\mathrm{S} 41, \mathrm{~S} 42}$ in Gaussian $03^{\mathrm{S} 33}$ for the two initial helices of the AM1-optimized types I (Figure 3) and III (Figure S8). The B3LYP/6-31G(d,p) ${ }^{\mathrm{S} 33-\mathrm{S} 35}$ was applied to the boundary sequence $\left(\mathrm{C}^{\alpha}-\mathrm{CO}-\mathrm{Ala}_{4}-\mathrm{Aib}-\Delta^{\mathrm{Z}} \mathrm{Phe}-\mathrm{NH}-\mathrm{C}^{\alpha}\right)$ at the high layer, while the $\mathrm{AM} 1^{15, \mathrm{~S} 33}$ was set to the other part at the low layer. ${ }^{\mathrm{S} 42-\mathrm{S} 44}$ Energy minimization at the ONIOM was carried out for the initial structures of the types I and III. ${ }^{15, \mathrm{~S} 33-\mathrm{S} 35, \mathrm{~S} 41-\mathrm{S} 44}$

Figure S12 shows a heterochiral helix of Ac-L-Ala $2_{20}-\left(\text { Aib- } \Delta^{Z} \mathrm{Phe}\right)_{4}-\mathrm{Aib}-\mathrm{OMe}$ energy-minimized from the type I. Its backbone torsion angles and the important hydrogen-bond parameters are shown in Figure S13 and Table S3, respectively. Interestingly, the heterochiral type III adopting a relatively straight form was also converged to a bending form similar to Figure S12. Simulation at the high precision demonstrates that the heterochiral helix energetically favors a bending form. In Figure S12, the $\mathrm{CH}-\pi$ interaction was also suggested between the $1-6$ residues, in which one $\mathrm{H}^{\beta}$ of $\mathrm{Ala}(17)$ and phenyl-ring center were placed at a distance of $2.8 \AA$. At the boundary sequence, a hydrogen bond of $6 \rightarrow 1$ type was also found together with that of $5 \rightarrow 2$ type. From Table S3, the former hydrogen bond is judged to be more stable than the latter type. Although similar tendency was found in the AM1-based simulation, the difference in stabilities of $6 \rightarrow 1$ and $5 \rightarrow 2$ types became more prominent at the DFT/AM1 (ONIOM) level. Intriguingly, the prediction is consistent with the experimental proposal that the $6 \rightarrow 1$ type is superior to the $5 \rightarrow 2$ type in hydrogen-bonding stability in other helical oligopeptides containing the Schellman-motif. ${ }^{7 \mathrm{a}, \mathrm{S} 19 \mathrm{c}}$ 

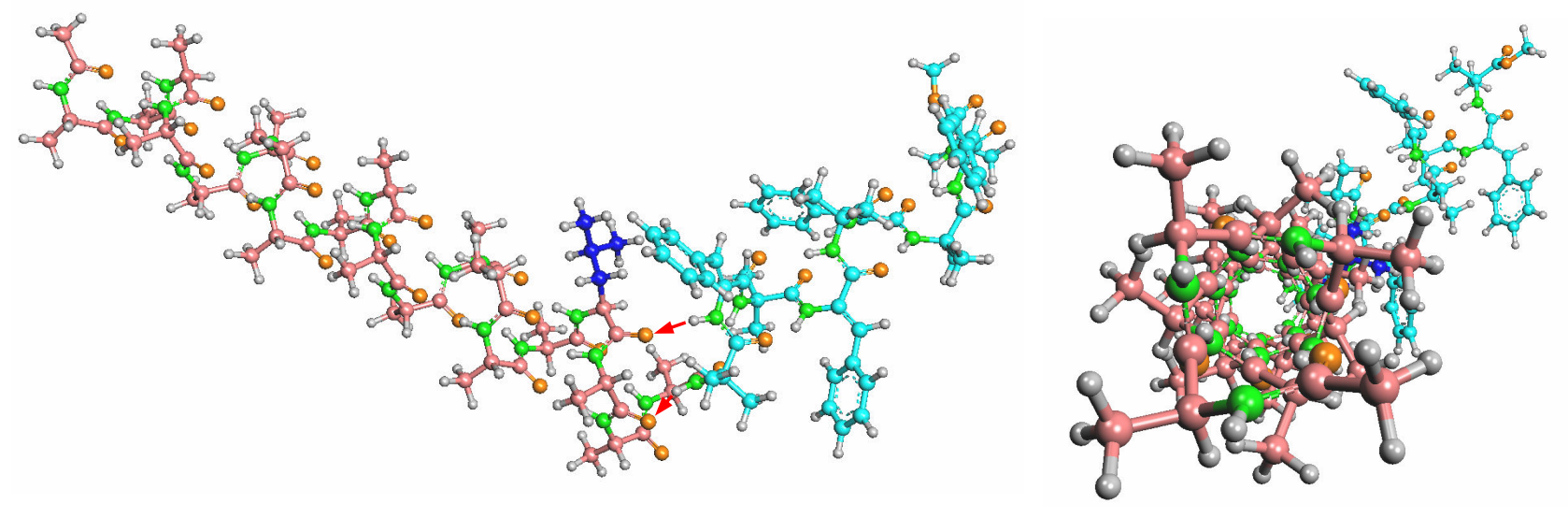

Figure S10. Heterochiral helix of Ac-L-Ala 16 -L-Leu-L-Ala $3-\left(\text { Aib- } \Delta^{Z}{ }^{\mathrm{Phe}}\right)_{4}-\mathrm{Aib}-\mathrm{OMe}$ simulated at the AM1 level. ${ }^{15, \mathrm{~S} 33}$ At the boundary, the $6 \rightarrow 1$ and $5 \rightarrow 2$ hydrogen bonds are indicated in the red arrows.

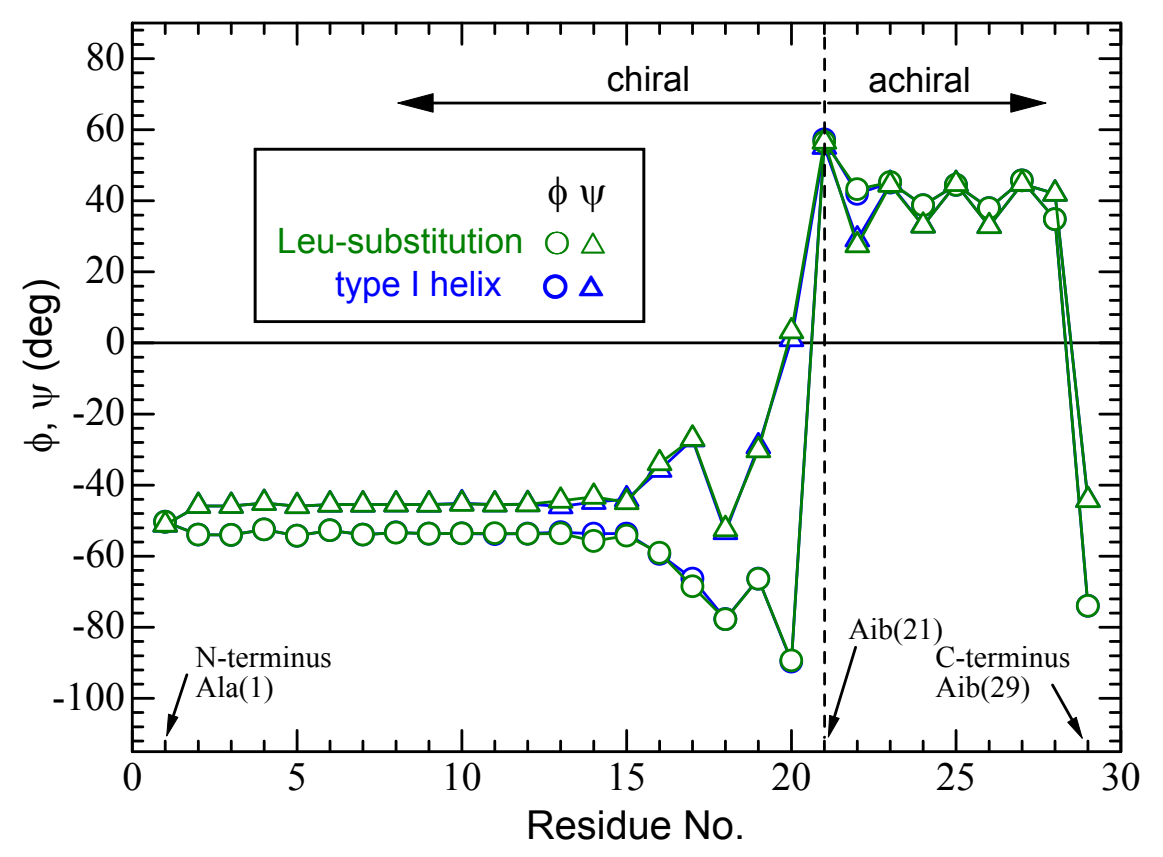

Figure S11. Main-chain torsion angles $(\phi, \psi)$ of each residue for Ac-L-Ala 16 -L-LeuL-Ala 3 -(Aib- $\Delta^{Z}$ Phe) $)_{4}$-Aib-OMe in the heterochiral helix (green) that corresponds to Figure S10. Those of type I helix of Ac-L-Ala $20-\left(\mathrm{Aib}-\Delta^{Z} \mathrm{Phe}\right)_{4}$-Aib-OMe [extracted from Figure S9 (type I)] are superimposed in blue. 


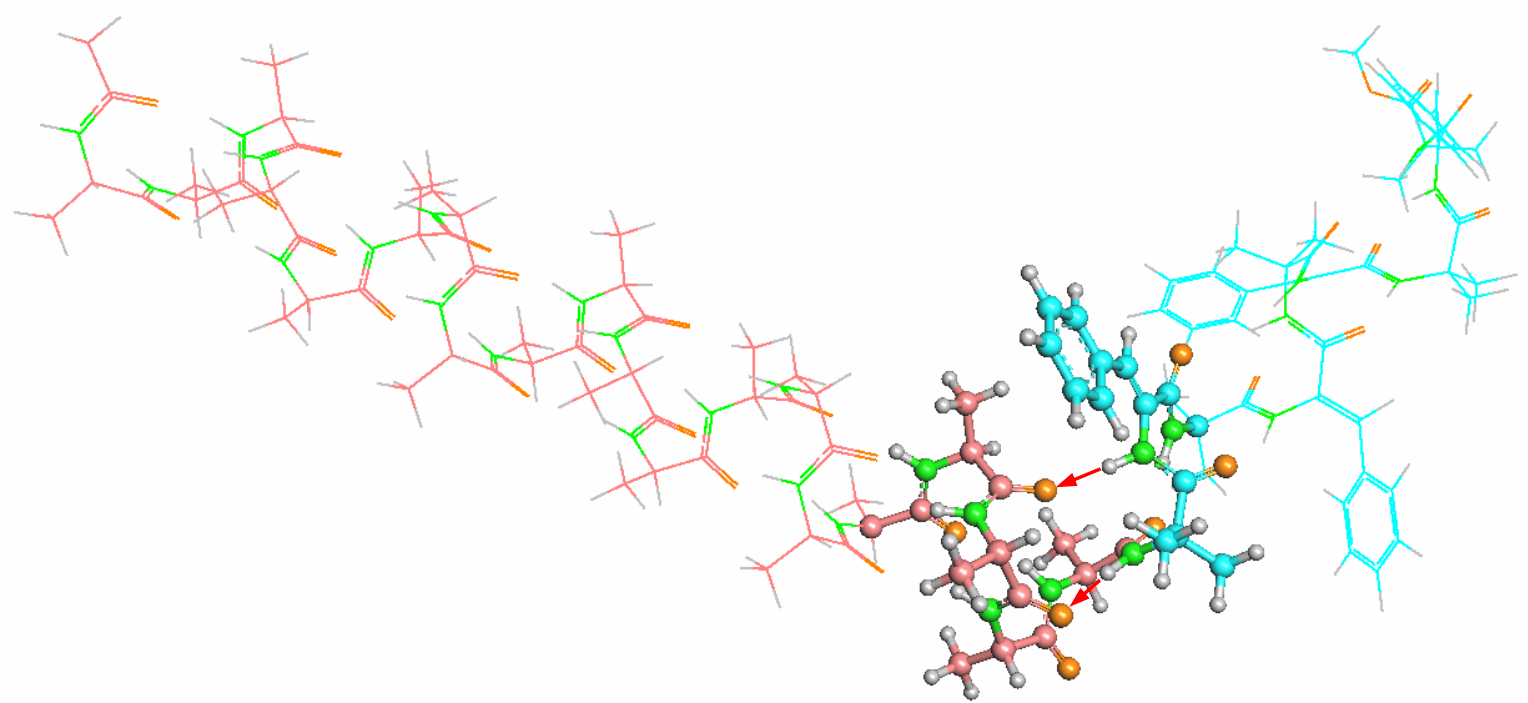

Figure S12. Heterochiral helix of Ac-L-Ala ${ }_{20}\left(\mathrm{Aib}-\Delta^{\mathrm{Z}} \mathrm{Phe}\right)_{4}-\mathrm{Aib}-\mathrm{OMe}$ simulated at the ONIOM method. ${ }^{15,333-535,541-544}$ The ball-stick backbone indicates the high layer at the DFT $[\mathrm{B} 3 \mathrm{LYP} / 6-31 \mathrm{G}(\mathrm{d}, \mathrm{p})]$ level, ${ }^{\mathrm{S} 33-\mathrm{S} 35}$ while the wire frame stands for the low layer at the AM1 level. ${ }^{15, \mathrm{S3} 3}$ At the boundary, the $6 \rightarrow 1$ and $5 \rightarrow 2$ hydrogen bonds are indicated in the red arrows.

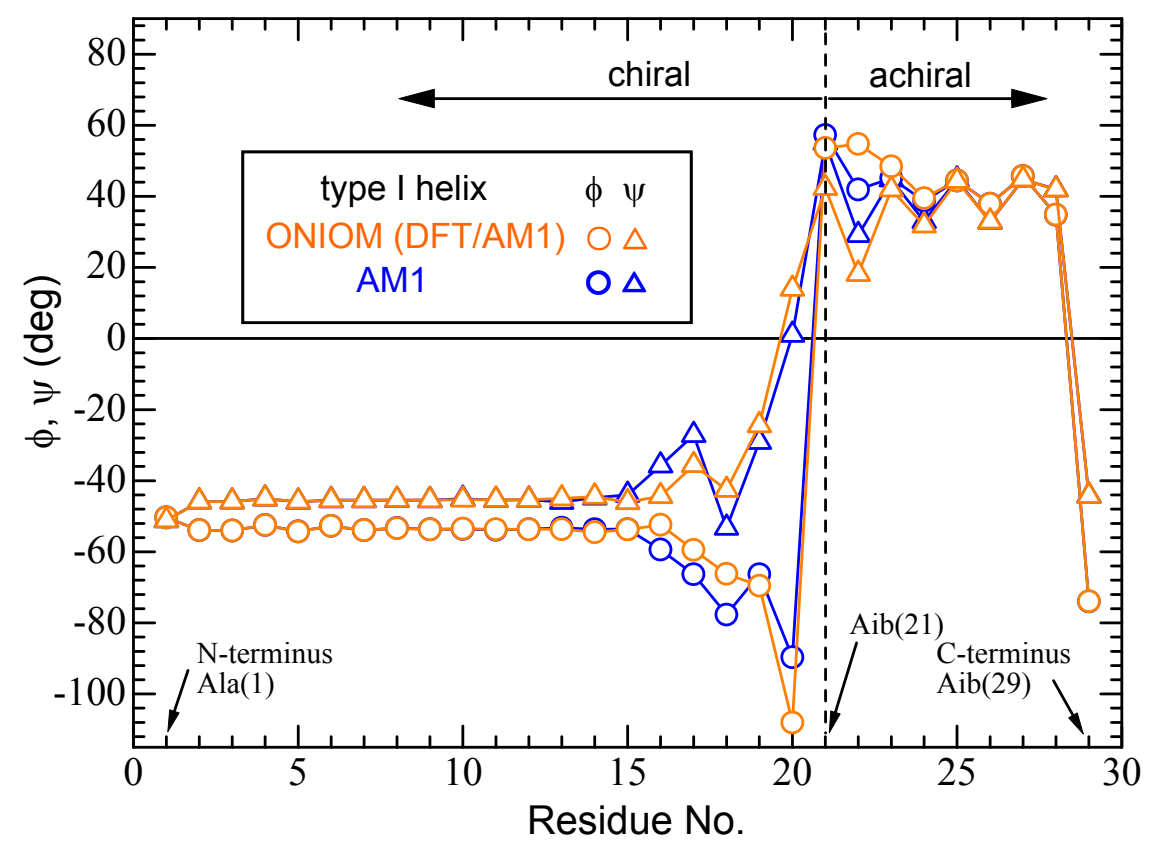

Figure S13. Main-chain torsion angles $(\phi, \psi)$ of each residue in Ac-L-Ala ${ }_{20}-\left(\mathrm{Aib}-\Delta^{\mathrm{Z}} \mathrm{Phe}\right)_{4}-\mathrm{Aib}-\mathrm{OMe}$ in heterochiral helix (orange) simulated at the ONIOM (DFT/AM1) method ${ }^{15,533-535,541-544}$ : $\mathrm{C}^{\alpha}$-CO-Ala(17)- - - - $\Delta^{Z} \mathrm{Phe}(22)-\mathrm{CO}-\mathrm{C}^{\alpha}$ for the high layer. This structure corresponds to Figure S12. Those of the type I helix of Ac-L-Ala ${ }_{20}-\left(\mathrm{Aib}-\Delta^{\mathrm{Z}} \mathrm{Phe}\right)_{4}$-Aib-OMe [extracted from Figure S9 (type I)] are superimposed in blue. 
Table S3. Parameters of the $6 \rightarrow 1$ and $5 \rightarrow 2$ hydrogen bonds at the Schellman-motif of heterochiral helix

\begin{tabular}{|c|c|c|c|c|c|c|}
\hline \multirow{3}{*}{$\begin{array}{l}\text { helix type } \\
\text { type I helix }{ }^{\mathrm{a}}\end{array}$} & \multicolumn{2}{|c|}{ hydrogen bond type } & \multirow{2}{*}{ 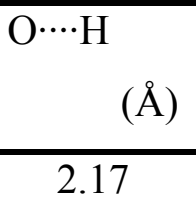 } & \multirow{2}{*}{$\begin{array}{l}\mathrm{O} \cdots \mathrm{N} \\
\frac{(\AA)}{3.14}\end{array}$} & \multirow{2}{*}{$\begin{array}{r}\mathrm{C}=\mathrm{O} \cdots \mathrm{H} \\
\left(^{\circ}\right)\end{array}$} & \multirow{2}{*}{$\begin{array}{r}\mathrm{O} \cdots \mathrm{H}-\mathrm{N} \\
\left({ }^{\circ}\right) \\
165\end{array}$} \\
\hline & $6 \rightarrow 1$ & $\operatorname{Ala}(17)-\Delta^{Z} \operatorname{Phe}(22)$ & & & & \\
\hline & $5 \rightarrow 2$ & $\mathrm{Ala}(18)-\mathrm{Aib}(21)$ & 2.26 & 3.19 & 98 & 154 \\
\hline Leu-substituted & $6 \rightarrow 1$ & $\operatorname{Leu}(17)-\Delta^{Z} \operatorname{Phe}(22)$ & 2.15 & 3.13 & 155 & 165 \\
\hline heterochiral helix ${ }^{b}$ & $5 \rightarrow 2$ & Ala $(18)-A i b(21)$ & 2.24 & 3.19 & 99 & 157 \\
\hline heterochiral helix & $6 \rightarrow 1$ & $\operatorname{Ala}(17)-\Delta^{Z} \operatorname{Phe}(22)$ & 1.99 & 3.01 & 154 & 174 \\
\hline at the $\mathrm{ONIOM}^{\mathrm{c}}$ & $5 \rightarrow 2$ & Ala $(18)-\mathrm{Aib}(21)$ & 2.47 & 3.46 & 99 & 163 \\
\hline
\end{tabular}

${ }^{\mathrm{a}, \mathrm{b}}$ Energy minimized at the AM1 level. ${ }^{15, \mathrm{~S} 33}{ }^{\mathrm{c}}$ Energy minimized at the ONIOM of DFT [B3LYP/6-31G(d,p)]/AM1 level. ${ }^{15, S 33-S 35, S 41-S 44}$

Validity of Heterochiral Helix Proposed. The dynamic occurrence of a heterochiral helix in NP is based on the following points.

(i) Nonapeptide sequence based on $-\left(\right.$ Aib- $\left.-\Delta^{Z} \mathrm{Phe}\right)-$ or $-\left(\Delta^{Z}\right.$ Phe-Aib $)$ - units adopts a typical $3_{10}$-helical conformation in the crystalline state or solution. ${ }^{6 \mathrm{e}-\mathrm{g}, 10, \mathrm{~S} 7, \mathrm{~S} 16}$ This conformational nature originates from high helix-forming propensity of Aib and $\Delta^{Z}$ Phe residues. ${ }^{S 21}$ Covalent or noncovalent incorporation of chiral residue(s) there gives rise to the imbalance of screw sense in the achiral sequence. $^{6 \mathrm{e}-\mathrm{g}, 8, \mathrm{~S} 7, \mathrm{~S} 16}$

(ii) Peptides N2-NP in most of solvents show split-CD spectra around $280 \mathrm{~nm}$. Recently, we performed simulation of electronic $C D$ spectra of analogous sequence $\left(\Delta^{Z}\right.$ Phe-X) in helical conformations. ${ }^{\mathrm{S} 12}$ According to the $\mathrm{CD}$-conformation relation, the split $\mathrm{CD}$ pattern around $280 \mathrm{~nm}$ indicates that the achiral backbone adopts a $3{ }_{10}$-helical conformation. ${ }^{\mathrm{S} 12}$ In most of solvents, an isodichronic point ${ }^{12}$ at the $\Delta^{Z}$ Phe-absorption band of around $280 \mathrm{~nm}$ is essentially found in N2-NP. Here the two states ${ }^{12}$ of right-handed and left-handed helices in the common achiral sequence are dynamically present with varying populations. In the hydrocarbon chlorides, the increase in length of the N-terminal L-sequence induces a left-handed helix sense in the achiral sequence.

(iii) CD spectra of NP show a large negative band at shorter wavelengths, being typical of a right-handed $\alpha$-helix. Especially in 2,2,2-trifluoroethanol, a pattern characteristic of $\alpha$-helix at the amide region is observed more clearly. $[\theta]_{222}$ and average number of amino acids $[33=24$ (Leu's) + 9 (achiral)] yielded a helix content of ca. $57 \%$ according to ref S45.

However, this modest content of helix will be underestimated, because the achiral sequence or its neighboring L-residues do not contribute to promotion of the CD pattern of $\alpha$-helix. Nonapeptides [H- $\beta$-Ala- $\Delta^{\mathrm{Z}} \mathrm{Phe}$-Aib- $\Delta^{\mathrm{Z}} \mathrm{Phe}-\mathrm{X}-\left(\Delta^{\mathrm{Z}} \mathrm{Phe}-\mathrm{Aib}\right)_{2}$-OMe $]$ taking a right-handed $3{ }_{10}$-helix show a split-type 
CD pattern around $280 \mathrm{~nm}$ with negative (at longer wavelength)-to-positive signs. ${ }^{\mathrm{S} b, \mathrm{~S} 12}$ Incidentally, a weaker split CD with the same signs was observed at amide region. ${ }^{\mathrm{S} 12}$ It was pointed out that the $\Delta^{Z}$ Phe-residue has an absorption band at amide region to disturb the ordinary CD analysis there. ${ }^{\text {S24a }} \mathrm{A}$ similar split pattern synchronized at the amide region seems to appear in peptides N1-N4 in several solvents (see Figure S5: for instance, tetrahydrofuran, ethanol, and methanol).

Thus, the CD pattern characteristic of an $\alpha$-helix in NP originates from the increasing number of L-Leu residues. From this point of view, the average number of residues should be set to the average Leu number (24) or smaller number in the calculation of helix content from $[\theta]_{222}$. Here the helix content of the Leu-sequence should be estimated to be about $81 \%{ }^{\mathrm{S} 45, \mathrm{~S} 46}$ or more. Accordingly the right-handed $\alpha$-helical sequence is bound to the achiral, helix-forming sequence to generate its screw sense. The split-CD pattern observed demonstrates that a heterochiral helix is numerically superior to a homochiral helix.

(iv) In the Schellman-motif, helix promotion in protein sequences is often terminated by Gly residue, ${ }^{3, \mathrm{~S} 38, \mathrm{~S} 39, \mathrm{~S} 47}$ whose the symmetric backbone adopts a left-handed helix without unfavorable steric constrains. ${ }^{2}$ When achiral Aib or $\Delta^{Z}$ Phe residue is put into a right-handed helical chain, a similar situation should occur. In fact, such examples are numerously found in synthetic helical peptides that achiral residue at $\mathrm{C}$-terminus or at the $\mathrm{C}$-side penultimate site adopts the opposite handedness of the preceding segment. ${ }^{7 \mathrm{a}-\mathrm{c}, \mathrm{S} 19 \mathrm{c}}$ In addition, helix inversion at internal achiral residue was proposed in synthetic peptides. ${ }^{7 \mathrm{c}}$

(v) Based on these experimental data, a heterochiral helix should be proposed, being composed of the right-handed $\alpha$-helical L-segment and the left-handed helical segment of achiral residues. The theoretical simulations at the semiemprical (AM1) ${ }^{15, \mathrm{~S} 33}$ or ONIOM (DFT/AM1) ${ }^{15, \mathrm{~S} 33-\mathrm{S} 35, \mathrm{~S} 41-\mathrm{S} 44}$ levels strongly support that the heterochiral helix is energetically permitted as a bending form.

Simulation of Heterochiral and Homochiral Helices for Peptides N4 and N5. Conformations of Ac-L-Ala $m$-(Aib- $\left.\Delta^{\mathrm{Z}} \mathrm{Phe}\right)_{4}$-Aib-OMe $(m=4$ and 5) were also simulated according to a manner similar to the preceding case of $m=20$. Four initial conformers, similarly generated in $m=20$, were subjected to the $\mathrm{AM} 1^{15, \mathrm{S3} 3}$-based energy minimization to yield two heterochiral and two homochiral helices. For the obtained structures, single-point DFT computation at the B3LYP/6-31G(d,p) ${ }^{\mathrm{S} 33-\mathrm{S} 35}$ was carried out. Their structures, energies and dipole moments for each of $m=4$ and 5 are summarized in Figures S14,S15 and Tables S4,S5. Whereas the energy values differed in the AM1-minimization and single-point DFT, we also used the DFT energy due to its higher accuracy. ${ }^{\text {S35 }}$

In each of $m=4$ and 5, right-handed 310 -helix as homochiral helix (type $\mathrm{D}$ for $m=4$; type $\mathrm{H}$ for $m=5$ ) was the most stable. Heterochiral helices of $m=4$ and 5, though having somewhat higher energy, were obtained as the local energy minima. A short turn of the helical Ala-sequence in $m=4$ 
and 5 enables to initiate a heterochiral helix. In addition, the $6 \rightarrow 1$ and $5 \rightarrow 2$ hydrogen bonds at the boundary sequence were found in the heterochiral type E of $m=5$ (see Figure S15).

In Tables S4 and S5, the DFT-energy difference in stable homochiral and heterochiral helices decreases with the Ala sequence length: $4.54(m=4) ; 3.69(m=5) ; 0.16(m=20)$. This tendency is consistent with the experimental tendency (Figures 2 and S6) that the achiral sequence favors a left-handed screw sense to adopt a heterochiral helix. ${ }^{\text {S48 }}$

Therefore, the nucleation model of a heterochiral helix through elongation of the L-sequence (Figure 1) has been demonstrated in both the experimental and theoretical aspects.

Table S4. Energy and Dipole Moment for Heterochiral and Homochiral Helices Predicted for Ac-L-Ala $m^{-}\left(\text {Aib- } \Delta^{Z} \text { Phe }\right)_{4}$-Aib-OMe $(m=4)^{\text {a }}$

\begin{tabular}{|c|c|c|c|c|}
\hline \multirow{2}{*}{} & \multicolumn{2}{|c|}{ heterochiral helix } & \multicolumn{2}{c|}{ homochiral helix } \\
\cline { 2 - 5 } & type A & type B & type C & type D \\
\hline energy difference $\left(\mathrm{kcal} \mathrm{mol}^{-1}\right)^{\mathrm{b}}$ & & & & \\
AM1 & +1.12 & +0.31 & +0.29 & 0.0 \\
DFT & +7.85 & +4.54 & +7.04 & 0.0 \\
\hline dipole moment (D) & & & & 45.6 \\
AM1 & 44.3 & 43.0 & 46.9 & 51.7 \\
\hline
\end{tabular}

${ }^{\mathrm{a}}$ In the DFT, single-point calculation at the B3LYP/6-31G(d,p) level ${ }^{\mathrm{S} 33-\mathrm{S} 35}$ was performed for the four structures energy-minimized from the AM1 method. ${ }^{15, \mathrm{~S} 33}$ bifference from the lowest energy (being set to zero).

Table S5. Energy and Dipole Moment for Heterochiral and Homochiral Helices Predicted for Ac-L-Ala $m^{-}\left(\text {Aib- } \Delta^{Z} \text { Phe }\right)_{4}$-Aib-OMe $(m=5)^{\text {a }}$

\begin{tabular}{|c|c|c|c|c|}
\hline \multirow{2}{*}{} & \multicolumn{2}{|c|}{ heterochiral helix } & \multicolumn{2}{c|}{ homochiral helix } \\
\cline { 2 - 5 } & type $\mathrm{E}$ & type $\mathrm{F}$ & type $\mathrm{G}$ & type $\mathrm{H}$ \\
\hline energy difference $\left(\mathrm{kcal} \mathrm{mol}^{-1}\right)^{\mathrm{b}}$ & & & & \\
AM1 & +0.21 & +0.76 & 0.0 & +0.32 \\
DFT & +3.96 & +3.69 & +7.05 & 0.0 \\
\hline dipole moment (D) & & & & \\
AM1 & 43.3 & 47.0 & 51.2 & 49.4 \\
DFT & 49.4 & 53.1 & 58.9 & 56.2 \\
\hline
\end{tabular}

${ }_{\mathrm{a}}^{\mathrm{a}}$ In the DFT, single-point calculation at the B3LYP/6-31G(d,p) level ${ }^{\mathrm{S} 33-\mathrm{S} 35}$ was performed for the four structures energy-minimized from the AM1 method. ${ }^{15, \mathrm{~S} 33}$ bifference from the lowest energy (being set to zero). 

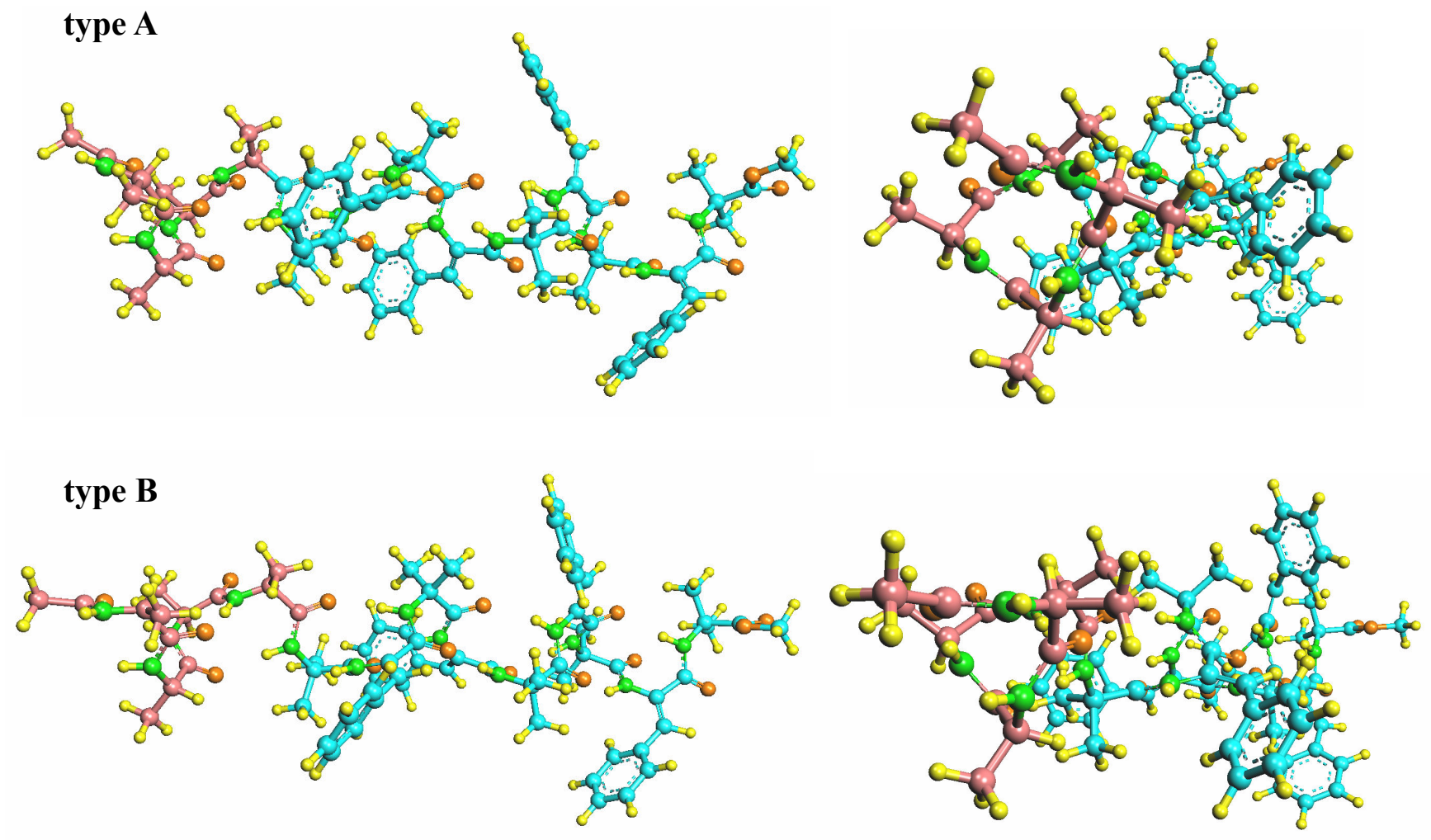

type C
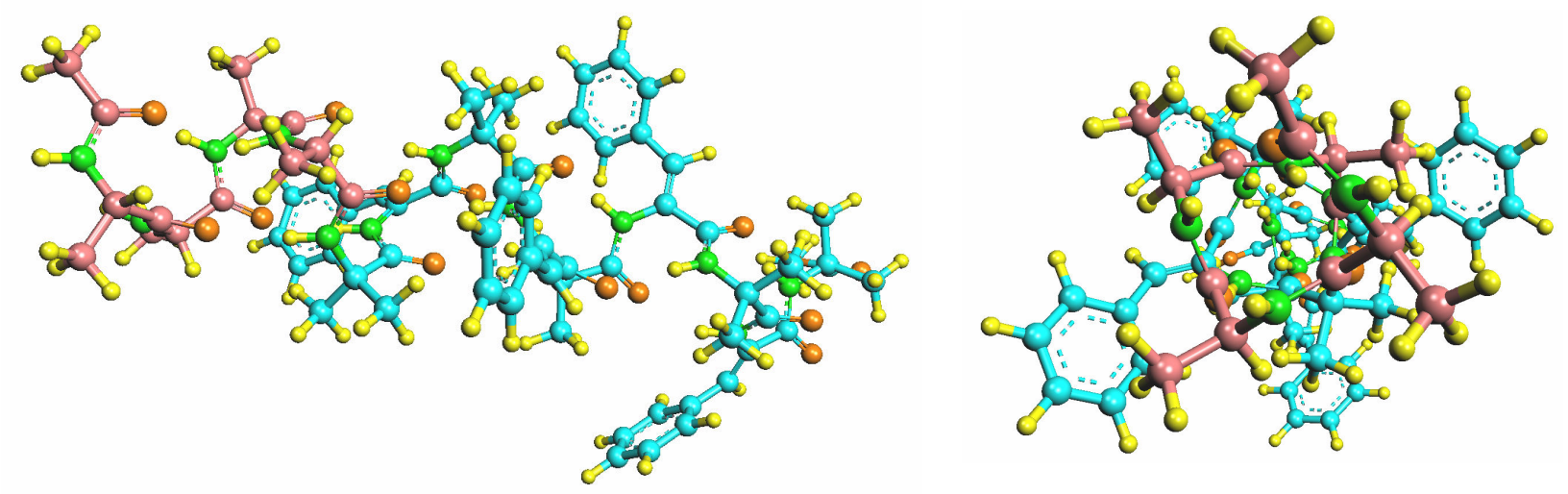

type D
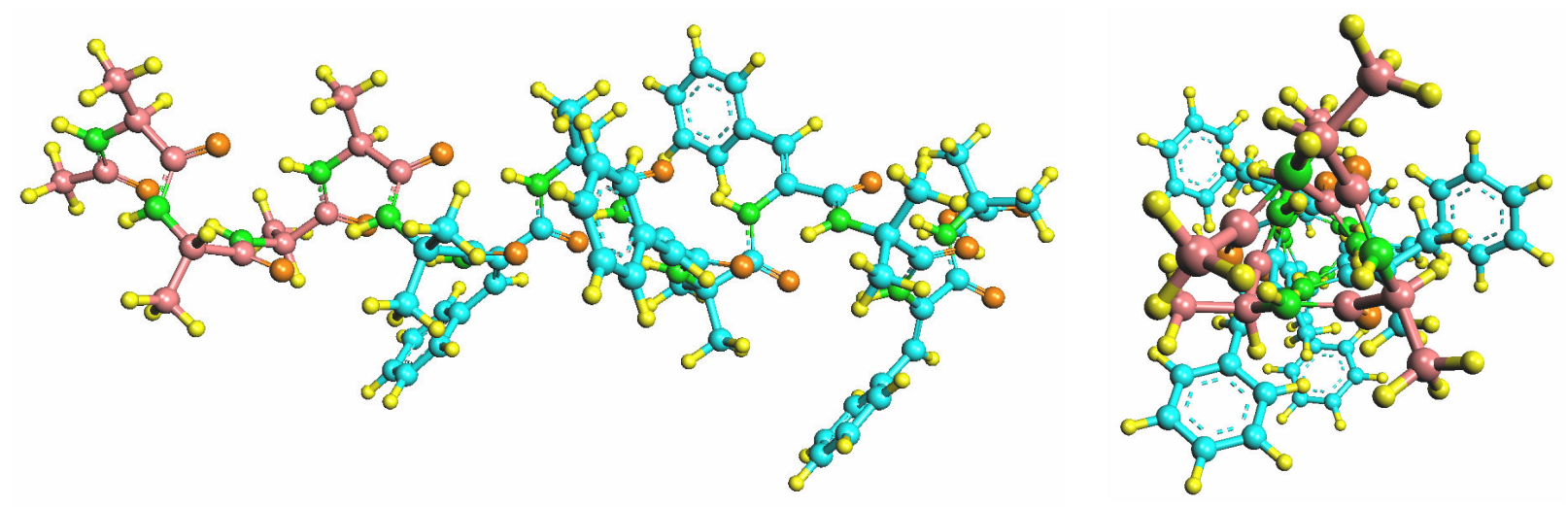

Figure S14. Heterochiral helices (types A, B) and homochiral helices (types C, D) theoretically simulated in Ac-L-Ala $m_{-}\left(\mathrm{Aib}-\Delta^{Z} \mathrm{Phe}\right)_{4}$-Aib-OMe $(m=4)$. These structures correspond to Table S4. 
type $E$
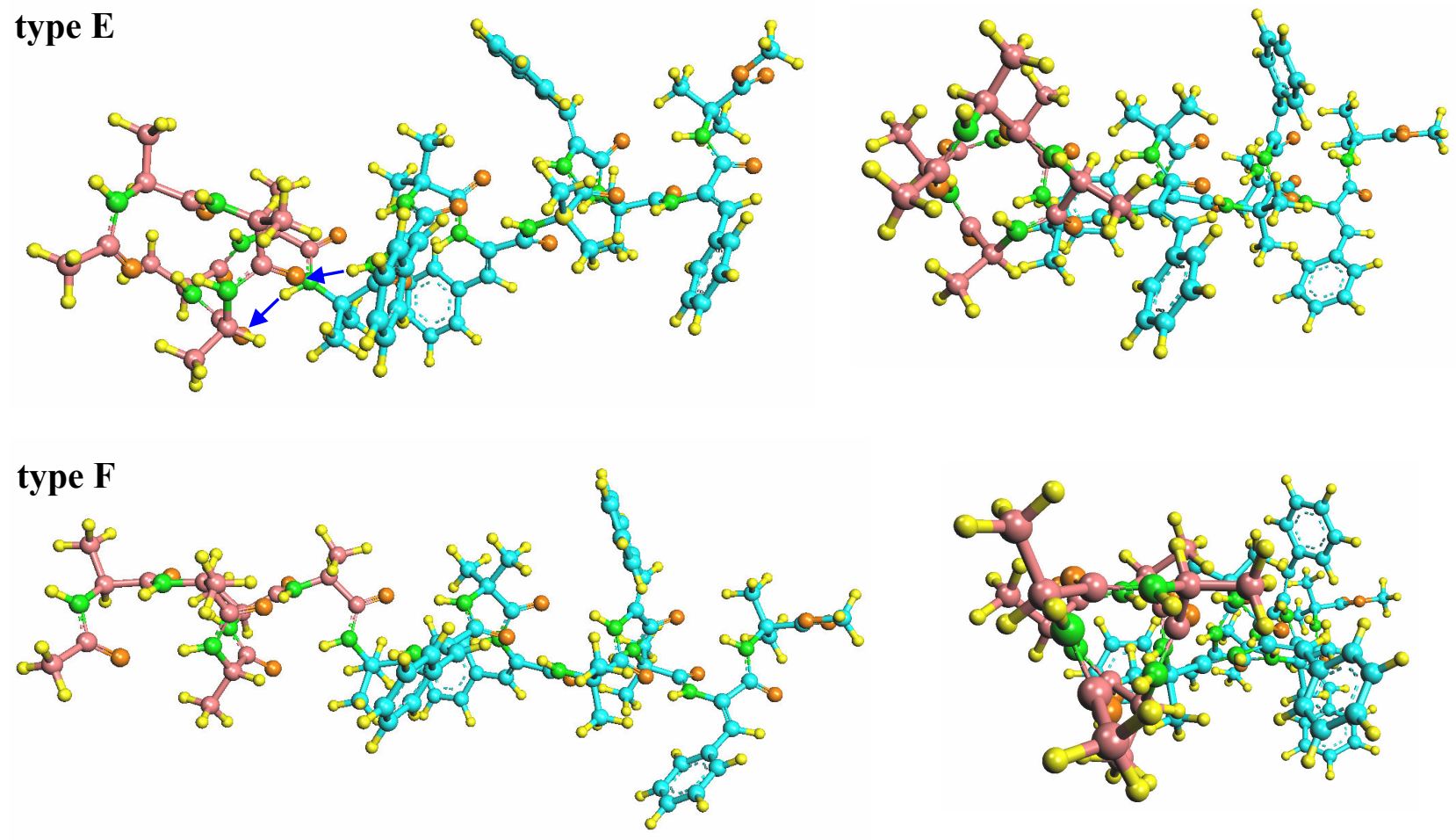

type $G$
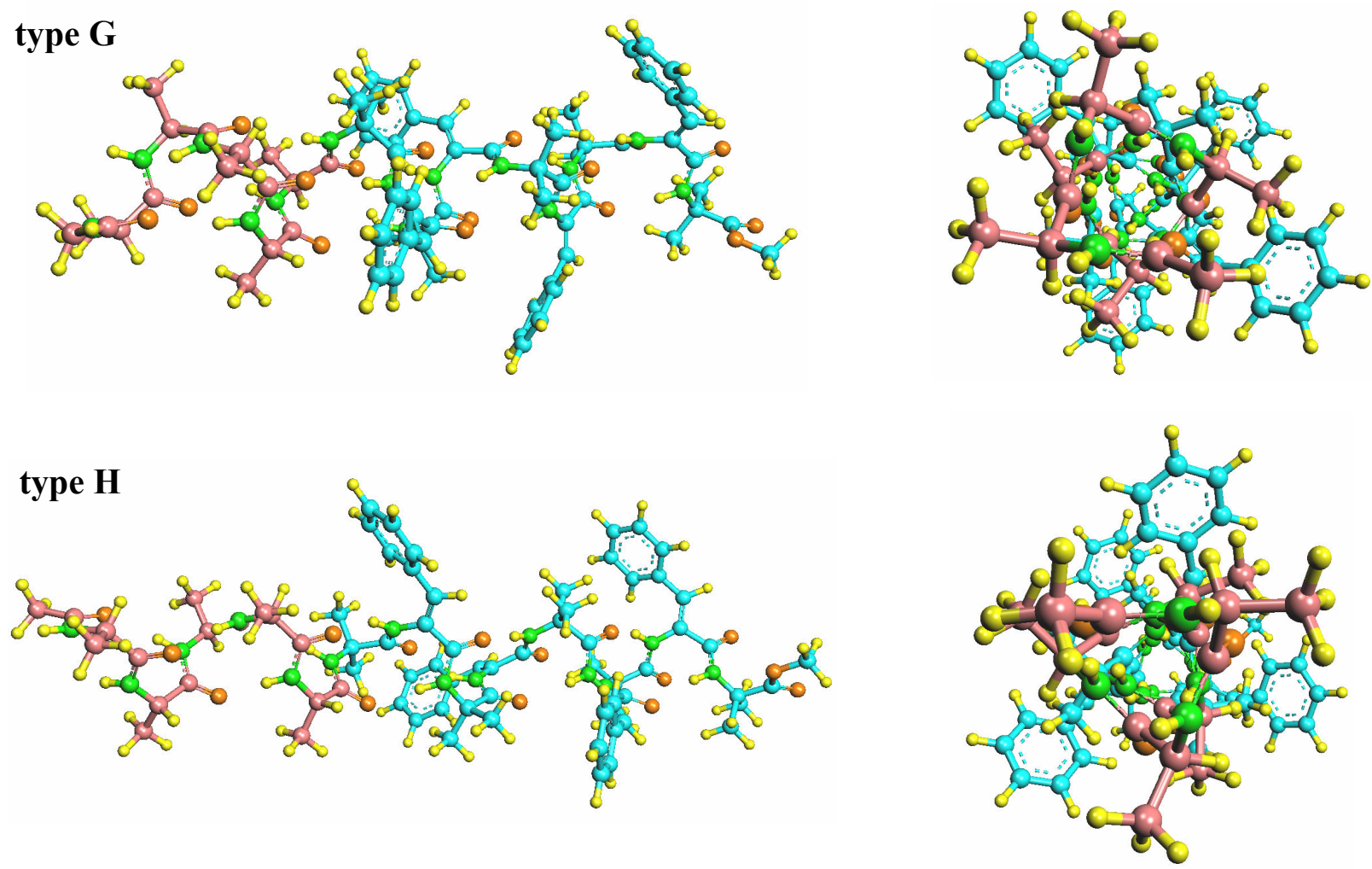

Figure S15. Heterochiral helices (types E, F) and homochiral helices (types G, H) theoretically simulated in Ac-L-Ala $m^{-}$(Aib- $\Delta^{Z}$ Phe $)_{4}$-Aib-OMe $(m=5)$. These structures correspond to Table S5. In type $\mathrm{E}$ (left), the $6 \rightarrow 1$ and $5 \rightarrow 2$ hydrogen bonds are indicated in the blue arrows. 
Theoretical Estimation of Solvent Effect on Heterochiral Helix. The preceding experimental and theoretical results strongly demonstrate that the propensity for a left-handed helix in the achiral sequence increases in the order of N4 $<\mathbf{N 5}<\mathbf{N P}$. In other words, nucleation and promotion of a heterochiral helix should be primarily addressed to the intrinsic nature of the backbone structure.

On the other hand, energy gap in heterochiral and homochiral helices, much or less, might be influenced by external factors. In the preceding theoretical treatments, solvent effects were not taken into account. We here have attempted solvent-mediated DFT [B3LYP/6-31G(d,p)] computation for the types I and II structures (shown in Figure 3) through the "PCM" method in Gaussian 03. ${ }^{\text {S3-S35,S49 }}$ A wide variety of solvents was chosen for the simulation: chloroform, dichloromethane, 1,2-dichloromethane, ethanol, acetonitrile, and water. Single-point DFT at the PCM method of these solvents $^{\mathrm{S} 50}$ yielded some energetic parameters in Gaussian 03-log file $\mathrm{S}^{\mathrm{S} 33 \mathrm{~S} 35}$ : that is, $"<\psi(\mathrm{f})|\mathrm{H}+\mathrm{V}(\mathrm{f}) / 2| \psi(\mathrm{f})>"(H V)$, "total free energy (having all non electrostatic terms) in solution" $(F E)$, "(polarized solute) minus solvent" (PS), and "total non-electrostatic" (NE) were extracted ${ }^{\mathrm{S} 50}$ (for the meaning of these energetic parameters, see refs S33,S49).

In terms of each parameter, the difference in types I and II $\left(\Delta \mathrm{E}_{\mathrm{I}-\mathrm{II}}=\mathrm{E}_{\mathrm{I}}-\mathrm{E}_{\mathrm{II}}\right)$ was plotted against the dielectric constant of each solvent (Figure S16A). On the whole, these parameters of the heterochiral type I became smaller than the corresponding ones of the homochiral type II. In contrast, the homochiral type II was slightly stable in vacuum (Table S2). Thus the bending form of type I should undergo more effective stabilization in solution, compared with the relatively straight form of type II. This prediction agrees with the fact that peptide NP adopts a heterochiral helix in most of solvents used here.

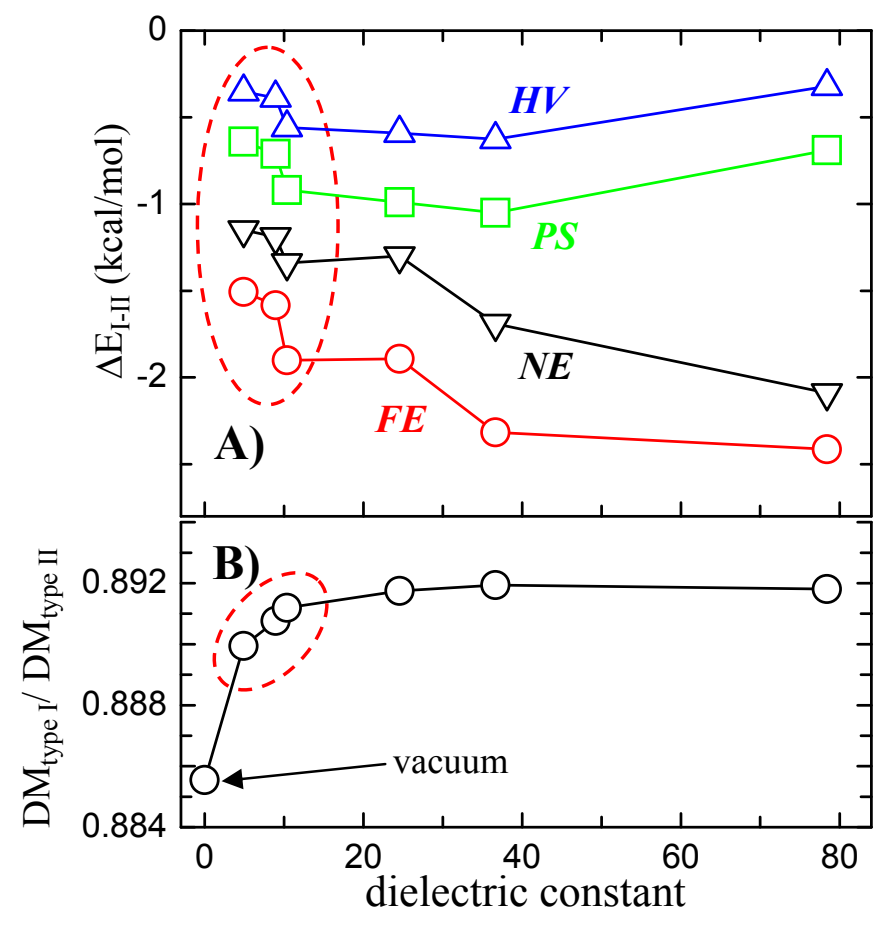

Figure S16. (A) Dependence of dielectric constant on difference between the energetic parameters of the types I and II helices $\left(\Delta \mathrm{E}_{\mathrm{I}-\mathrm{II}}\right)$. (B) The dipole moment ratio of type I/II ( $\left(\mathrm{DM}_{\text {typel }} / \mathrm{DM}_{\text {typeII }}\right)$ in each solvent: dielectric constant of zero corresponds to vacuum state. The dotted red circles belong to the hydrocarbon chlorides. 
Essentially, each difference in the types I and II tends to increase with solvent polarity. That is, the $\Delta \mathrm{E}_{\mathrm{I}-\mathrm{II}}$ magnitudes increased in the order of chloroform $<$ dichloromethane $<1,2$-dichloroethane (see Figure S16A, within the dotted red circle). This is consistent with the corresponding order in CD amplitude for a left-handed helix of the achiral sequence (see Figure S17). ${ }^{\text {S51 }}$ However, the CD amplitude decreased with the solvent polarity higher than the hydrocarbon chlorides. Thus comprehensive interpretation of the experimental tendency should need other factors: for instance, site-specific interactions in solute-solvent or structural fluctuations in solution.

A)

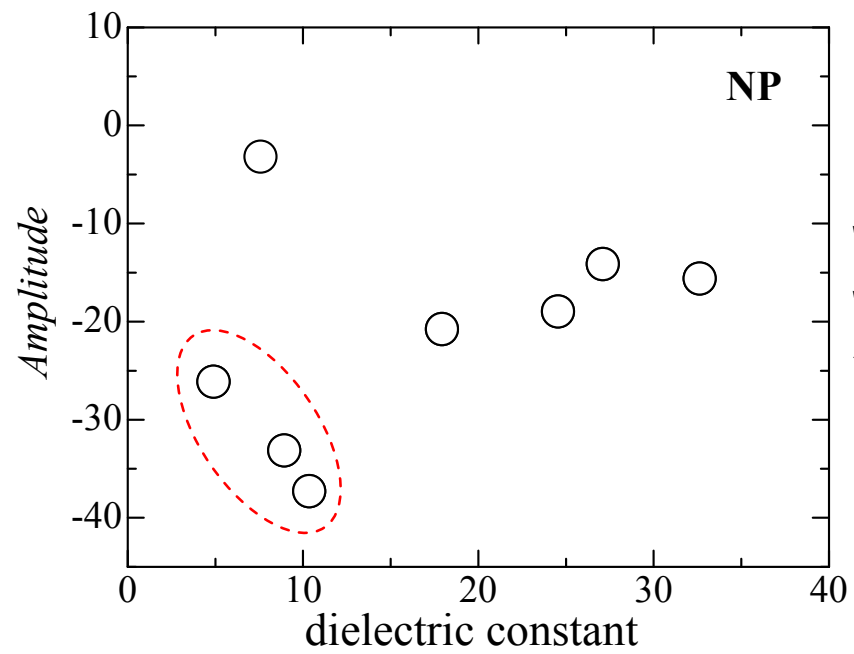

B)

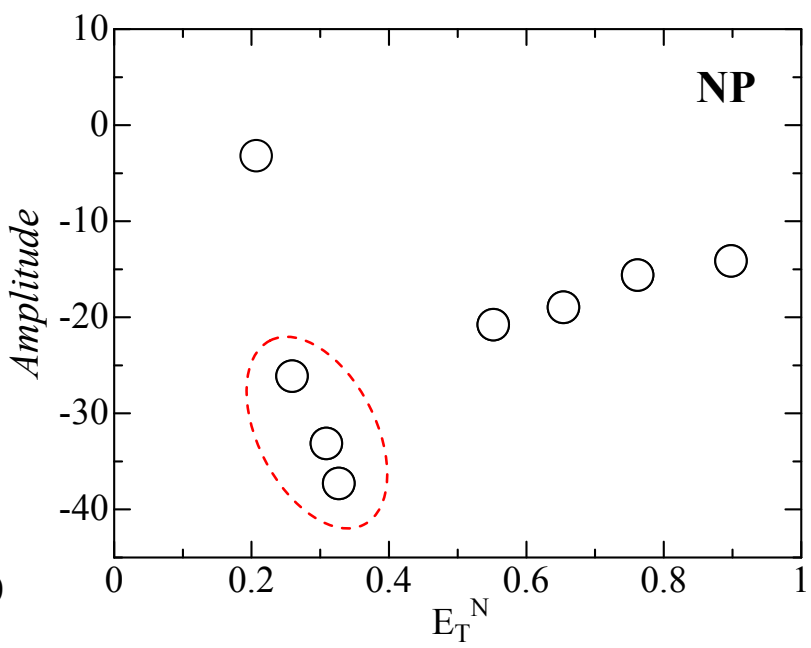

Figure S17. Influence of CD amplitude of NP by solvent parameters of (A) $\varepsilon$ and (B) $\mathrm{E}_{\mathrm{N}}^{\mathrm{T}}$. For these solvent parameters, see refs S33,S51. The dotted red circles belong to the hydrocarbon chlorides.

To understand the polarity of molecular surface, mapping of electrostatic potential from the total density of $\mathrm{SCF}^{\mathrm{S} 33, \mathrm{~S} 44}$ was carried out for the types I and II (whose the structures are shown in Figure 3). The resulting figures are displayed in Figure S18. Both peptides are composed of the positively-charged $\mathrm{N}$-terminal sequence and negatively-charged $\mathrm{C}$-terminal one. As a consequence, such large dipole moments (Table S2) are generated as widely recognized in protein helices. ${ }^{\text {S52 }}$ The dipole moment reduced in the heterochiral type I is visually understood in terms of the closer $\mathrm{N}$ - and C-termini (Figure S18). 
type I
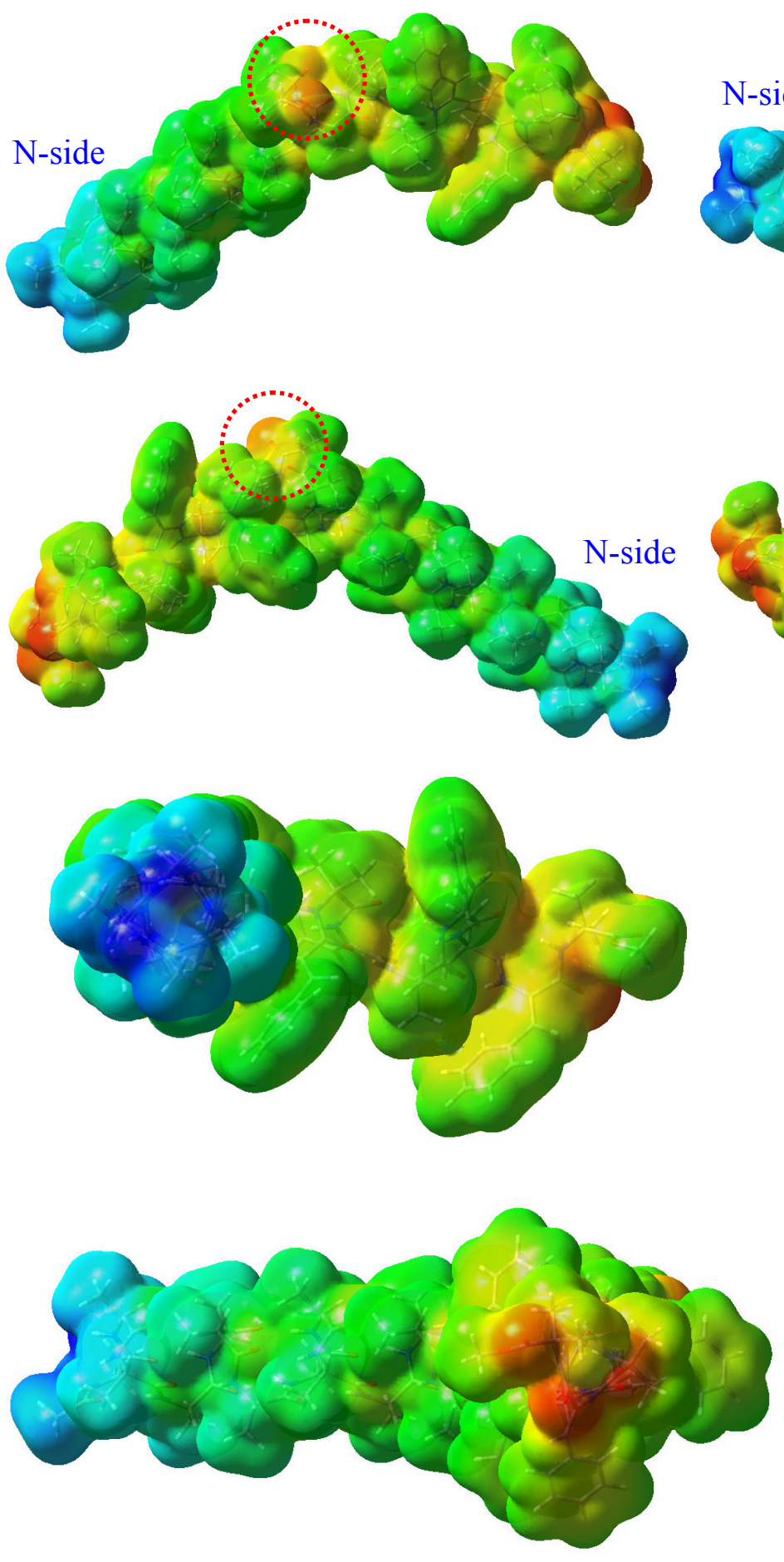

type II
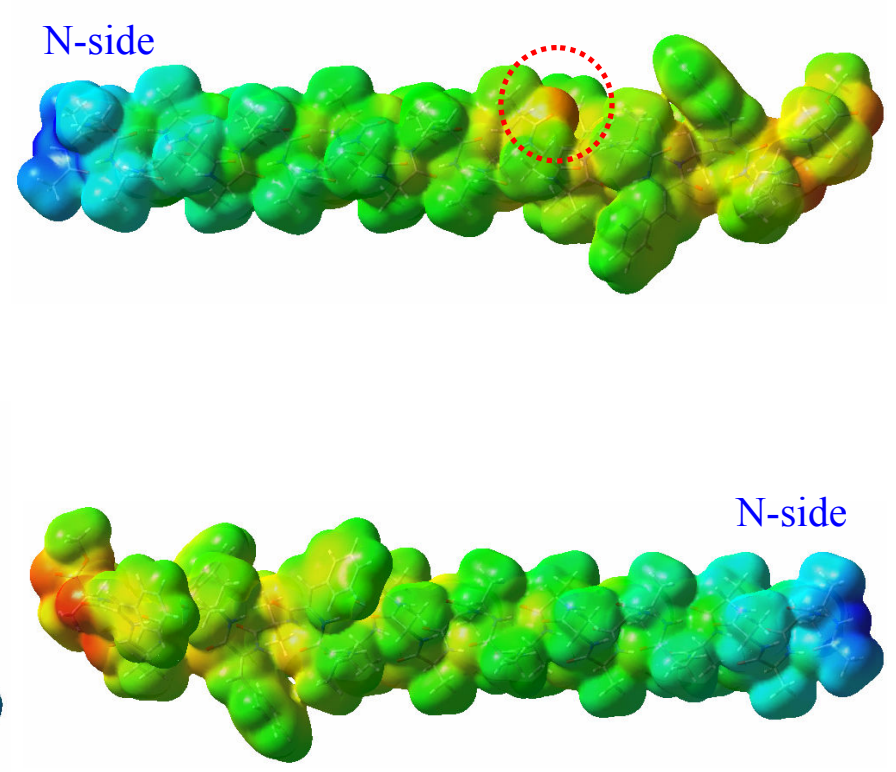
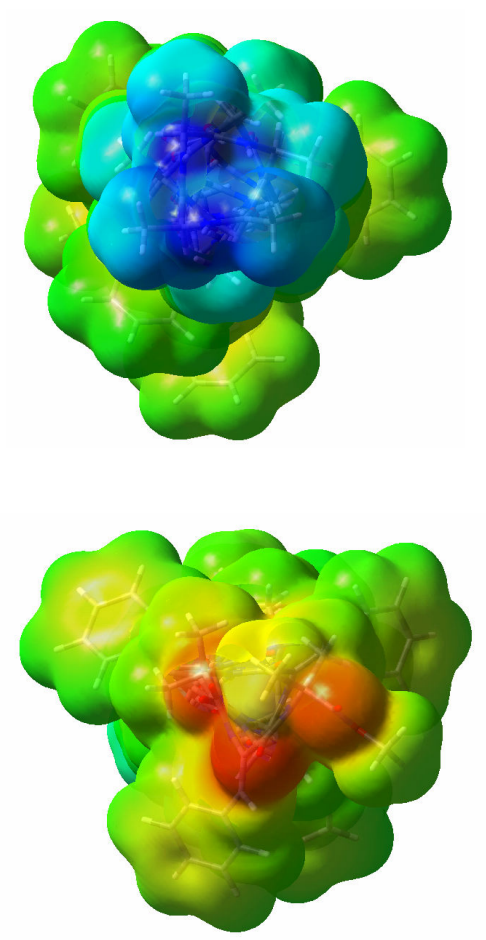

$-0.12$

Figure S18. Heterochiral helix (type I) and homochiral helix (type II) with electrostatic potentials mapped on the total density of SCF: "isoval" 444 was set to 0.001 . These molecular graphics were generated on the GaussView ${ }^{\mathrm{S} 44}$ using the single-point DFT results of the two structures (shown in Figure 3) in vacuum, whose the calculation was done in Table S2. Each helix is viewed in four directions: the lower two columns are viewed from the $\mathrm{N}$-terminal and $\mathrm{C}$-terminal sequences. The color bar (bottom) means that negatively- or positively-charged parts are expressed in red or blue, respectively. The dotted circles in red indicate negatively-charged boundary regions. 
In the heterochiral helix, negatively-charged parts at the boundary sequence are clearly exposed outside. Thus, polar solvent molecules should be readily accessible not only to the terminal sequences, but also to the chiral/achiral boundary. Although a similar site is seen in the homochiral helix, it is located along the relatively straight backbone. Accordingly, the latter-type solvation might occur more effectively in the heterochiral helix, thereby influencing some solvent-mediated stabilization. The importance of such local solvation in helix C-capping structures also has been pointed out in other elegant systems. ${ }^{3 b, c, S 38, S 47}$

In addition, the dipole moment ratio of type I/type II increased slightly in vacuum to solution, or with solvent polarity (Figure S16B). Thus the partial charges on the heterochiral helix are pronounced by solvent polarity. In other words, solvation by polar solvent is also suggested to be somewhat more effective in the heterochiral helix.

Note Added in Proof. Estimation of the helix content was commented in refs S45 and S46. Additional citation of ref 1 was given in ref S53.

References and Notes (appended in this Supporting Information; reference numbers without the prefix "S" correspond to those in the original text.)

(S1) (a) Jain, R. M.; Rajashankar, K. R.; Ramakumar, S.; Chauhan, V. S. J. Am. Chem. Soc. 1997, 119, 3205-3211. (b) Pieroni, O.; Fissi, A.; Pratesi, C.; Temussi, P. A.; Ciardelli, F. Biopolymers 1993, 33, 1-10. (c) Inai, Y.; Kurokawa, Y.; Hirabayashi, T. Biopolymers 1999, 49, 551-564.

(S2) For general protocol for peptide synthesis, see: (a) Izumiya, N.; Kato, T.; Aoyagi, H.; Waki, M. Pepuchido Gosei no Kiso to Jikken (Principle and Practice of Peptide Synthesis); Maruzen Co., Ltd.: Tokyo, Japan, 1985; SciFinder Scholar, American Chemical Society, CAN 103:37731. (b) Jones, J. The Chemical Synthesis of Peptides, Oxford University Press, Oxford, USA, 1991.

(S3) For deprotection of N-Boc group with formic acid, see: Halpern, B.; Nitecki, D. E. Tetrahedron Lett. 1967, 8, 3031-3033. See also ref S2a.

(S4) For precise weight of each atom, see: de Laeter, J. R.; Böhlke, J. K.; De Bièvre, P.; Hidaka, H.; Peiser, H. S.; Rosman, K. J. R.; Taylor, P. D. P. Pure Appl. Chem. 2003, 75, 683-800.

(S5) Renée, W.; Shahriar, M. J. Org. Chem. 1992, 57, 2755-2756.

(S6) A similar design of a helical polypeptide was carried out through NCA polymerization with N-amino group of an oligopeptide, see: (a) Inai, Y.; Sisido, M.; Imanishi, Y. J. Phys. Chem. 1990, 94, 6237-6243. (b) Inai, Y.; Sisido, M.; Imanishi, Y. J. Phys. Chem. 1991, 95, $3847-3851$.

(S7) (a) Ousaka, N.; Inai, Y.; Okabe, T. Biopolymers 2006, 83, 337-351. (b) Inai, Y.; Komori, H. Biomacromolecules 2004, 5, 1231-1240.

(S8) Bodenhausen, G.; Kogler, H.; Ernst, R. R. J. Magn. Reson. 1984, 58, 370-388. 
(S9) Bax, A.; Davis, D. G. J. Magn. Reson. 1985, 65, 355-360.

(S10) Marat, K. SpinWorks, University of Manitoba, Canada, 1999-2006 (http://www.umanitoba.ca/chemistry/nmr/spinworks/index.html).

(S11) For a detailed review for NMR analysis of biopolymers, see: Wüthrich, K. NMR of Proteins and Nucleic Acids; John Wiley and Sons: New York, 1986.

(S12) Komori, H.; Inai, Y. J. Phys. Chem. A 2006, 110, 9099-9107.

(S13) Pieroni, O.; Montagnoli, G.; Fissi, A.; Merlino, S.; Ciardelli, F. J. Am. Chem. Soc. 1975, 97, $6820-6826$.

(S14) For technical information about MALDI-TOF mass, see: Jagtap, R. N.; Ambre, A. H. Bull. Mater. Sci. 2005, 28, 515-528.

(S15) (a) Kennedy, D. F.; Crisma, M.; Toniolo, C.; Chapman, D. Biochemistry 1991, 30, 6541-6548. (b) Inai, Y.; Sakakura, Y.; Hirabayashi, T. Polym. J. 1998, 30, 828-832.

(S16) (a) Inai, Y.; Ishida, Y.; Tagawa, K.; Takasu, A.; Hirabayashi, T. J. Am. Chem. Soc. 2002, 124, 2466-2473. (b) Inai, Y.; Komori, H.; Takasu, A.; Hirabayashi, T. Biomacromolecules 2003, 4, 122-128. (c) Inai, Y.; Hirano, T. ITE Lett. Batt. New. Technol. Med. 2003, 4, 485-488.

(S17) Pitner, T. P.; Urry, D. W. J. Am. Chem. Soc. 1972, 94, 1399-1400.

(S18) For examples of the $\left(\mathrm{CD}_{3}\right)_{2} \mathrm{SO}$ addition experiment, see refs $6 \mathrm{~d}-\mathrm{g}, 10, \mathrm{~S} 1, \mathrm{~S} 7, \mathrm{~S} 16, \mathrm{~S} 17, \mathrm{~S} 19$.

(S19) (a) Toniolo, C.; Bonora, G. M.; Bavoso, A.; Benedetti, E.; Di Blasio, B.; Pavone, V.; Pedone, C. Macromolecules 1986, 19, 472-479. (b) Toniolo, C.; Crisma, M.; Bonora, G. M.; Benedetti, E.; Di Blasio, B.; Pavone, V.; Pedone, C.; Santini, A. Biopolymers 1991, 31, 129-138. (c) Datta, S.; Shamala, N.; Banerjee, A.; Pramanik, A.; Bhattacharjya, S.; Balaram, P. J. Am. Chem. Soc. 1997, 119, 9246-9251.

(S20) For 3 $3_{10}$-helical structure, see: (a) Toniolo, C.; Benedetti, E. Trends Biochem. Sci. 1991, 16, 350-353. (b) Barlow, D. J.; Thornton, J. M. J. Mol. Biol. 1988, 201, 601-619.

(S21) Helical conformations of peptides containing Aib or $\Delta^{Z}$ Phe residues have been reported: for the Aib residue, see refs 4a,7a,c,9b,S19,S22; for the $\Delta^{Z}$ Phe residue, see refs 4b,6d,S1a,b,S23.

(S22) (a) Venkatraman, J.; Shankaramma, S. C.; Balaram, P. Chem. Rev. 2001, 101, 3131-3152. (b) Marshall, G. R.; Hodgkin, E. E.; Langs, D. A.; Smith, G. D.; Zabrocki, J.; Leplawy, M. T. Proc. Natl. Acad. Sci. U.S.A. 1990, 87, 487-491. (c) Toniolo, C.; Benedetti, E. Macromolecules 1991, 24, 4004-4009. (d) Yasutomi, S.; Morita, T.; Imanishi, Y.; Kimura S. Science 2004, 304, 1944-1947. (e) Karle, I. L.; Flippen-Anderson, J. L.; Uma, K.; Balaram, H.; Balaram, P. Proc. Natl. Acad. Sci. U.S.A. 1989, 86, 765-769. (f) Okuyama, K.; Saga, Y.; Nakayama, M.; Narita M. Biopolymers 1991, 31, 975-985. (g) Toniolo, C.; Bonora, G. M.; Bavoso, A.; Benedetti, E.; Di Blasio, B.; Pavone, V.; Pedone, C. Biopolymers 1983, 22, 205-215.

(S23) (a) Jain, R.; Chauhan, V. S. Biopolymers 1996, 40, 105-119. (b) Ciajolo, M. R.; Tuzi, A.; 
Pratesi, C. R.; Fissi, A.; Pieroni, O. Biopolymers 1992, 32, 717-724. (c) Padmanabhan, B.;

Singh, T. P. Biopolymers 1993, 33, 613-619.

(S24) For CD analysis in $\Delta^{Z}$ Phe-containing peptides, see: (a) Pieroni, O.; Fissi, A.; Jain, R. M.; Chauhan, V. S. Biopolymers 1996, 38, 97-108. For the "exciton chirality method", see: (b) Harada, N.; Nakanishi, K. Circular Dichroic Spectroscopy. Exciton Coupling in Organic Stereochemistry; University Science Books: Mill Valley, CA, 1983. (c) Harada, N.; Chen, S. L.; Nakanishi, K. J. Am. Chem. Soc. 1975, 97, 5345-5352.

(S25) Inai, Y.; Ousaka, N.; Ookouchi, Y. Biopolymers 2006, 82, 471-481.

(S26) (a) Trewhella, J.; Liddle, W. K.; Heidorn, D. B.; Strynadka, N. Biochemistry 1989, 28, 1294-1301. (b) Dong, A.; Caughey, W. S.; Du Clos, T. W. J. Biol. Chem. 1994, 269, 6424-6430.

(c) Bramanti, E.; Benedetti, E.; Sagripanti, A.; Papineschi, F.; Benedetti, E. Biopolymers 1997, $41,545-553$.

(S27) For a similar treatment, see: Inai, Y.; Kurokawa, Y.; Kojima, N. J. Chem. Soc., Perkin Trans. 2 2002, 1850-1857. See also ref S7b. For theoretical treatment of split-CD amplitudes, see $\mathrm{S} 24 \mathrm{~b}, \mathrm{c}$.

(S28) (a) Arnott, S.; Dover, S. D. J. Mol. Biol. 1967, 30, 209-212. (b) Arnott, S.; Wonacott, A. J. J. Mol. Biol. 1966, 21, 371-383. (c) IUPAC-IUB Commission on Biochemical Nomenclature, Biochemistry 1970, 9, 3471-3479. For definition of torsion angles, see ref S28c.

(S29) (a) Paterson, Y.; Rumsey, S. M.; Benedetti, E.; Némethy, G.; Scheraga, H. A. J. Am. Chem. Soc. 1981, 103, 2947-2955. (b) Venkatachalam, C. M. Biopolymers 1968, 6, 1425-1436.

(S30) For software for the initial modeling and its references, see: (a) Sisido, M. Pept. Chem. 1992, 1991, 105-110. (b) Inai, Y.; Ito, T.; Hirabayashi, T.; Yokota, K. Biopolymers 1993, 33, 1173-1184. (c) Momany, F. A.; McGuire, R. F.; Burgess, A. W.; Scheraga, H. A. J. Phys. Chem. 1975, 79, 2361-2381. (d) Beppu, Y. Comput. Chem. 1989, 13, 101. (e) Aubry, A.; Allier, F.; Boussard, G.; Marraud, M. Biopolymers 1985, 24, 639-646. (f) Ajò, D.; Casarin, M.; Granozzi, G.; Busetti, V. Tetrahedron 1981, 37, 3507-3512. See also ref S7b,S29a.

(S31) The two $\chi^{2}$-orientations were theoretically predicted: (a) Ajò, D.; Casarin, M.; Granozzi, G. $J$. Mol. Struct. (THEOCHEM) 1982, 86, 297-300. Recently, simulation of electronic CD spectra was carried out in helical nonapeptides repeating $-\left(\Delta^{Z}\right.$ Phe-X $)-$. Here split-type CD patterns were predicted in the $3{ }_{10}$-helical backbone having $\Delta^{Z}$ Phe-side chains in vertical orientations to the helix axis. ${ }^{\mathrm{S} 12}$ Since the present CD spectra showed a split pattern, similar side-chain orientations were applied to the initial conformers of the present achiral sequence.

(S32) See refs S19a,S22b,e-g. See also: Inai, Y.; Oshikawa, T.; Yamashita, M.; Hirabayashi, T.; Ashitaka, S. J. Chem. Soc., Perkin. Trans. 2 2001, 892-897. For helix inversion in more native sequences, see ref 3 . 
(S33) (a) Frisch, M. J.; Trucks, G. W.; Schlegel, H. B.; Scuseria, G. E.; Robb, M. A.; Cheeseman, J. R.; Montgomery, Jr., J. A.; Vreven, T.; Kudin, K. N.; Burant, J. C.; Millam, J. M.; Iyengar, S. S.; Tomasi, J.; Barone, V.; Mennucci, B.; Cossi, M.; Scalmani, G.; Rega, N.; Petersson, G. A.; Nakatsuji, H.; Hada, M.; Ehara, M.; Toyota, K.; Fukuda, R.; Hasegawa, J.; Ishida, M.; Nakajima, T.; Honda, Y.; Kitao, O.; Nakai, H.; Klene, M.; Li, X.; Knox, J. E.; Hratchian, H. P.; Cross, J. B.; Bakken, V.; Adamo, C.; Jaramillo, J.; Gomperts, R.; Stratmann, R. E.; Yazyev, O.; Austin, A. J.; Cammi, R.; Pomelli, C.; Ochterski, J. W.; Ayala, P. Y.; Morokuma, K.; Voth, G. A.; Salvador, P.; Dannenberg, J. J.; Zakrzewski, V. G.; Dapprich, S.; Daniels, A. D.; Strain, M. C.; Farkas, O.; Malick, D. K.; Rabuck, A. D.; Raghavachari, K.; Foresman, J. B.; Ortiz, J. V.; Cui, Q.; Baboul, A. G.; Clifford, S.; Cioslowski, J.; Stefanov, B. B.; Liu, G.; Liashenko, A.; Piskorz, P.; Komaromi, I.; Martin, R. L.; Fox, D. J.; Keith, T.; Al-Laham, M. A.; Peng, C. Y.; Nanayakkara, A.; Challacombe, M.; Gill, P. M. W.; Johnson, B.; Chen, W.; Wong, M. W.; Gonzalez, C.; and Pople, J. A. Gaussian 03, Revision C.02; Gaussian, Inc., Wallingford CT, 2004. For the manuals and full references in Gaussian 03, see: (b) The Official Gaussian Website (http://www.gaussian.com); (c) Frisch, Æ.; Frisch, M. J. Gaussian 98 User's Reference, second edition, Gaussian, Inc., Pittsburg, PA, USA, 1999.

(S34) (a) Stephens, P. J.; Devlin, F. J.; Chabalowski, C. F.; Frisch, M. J. J. Phys. Chem. 1994, 98, 11623-11627. (b) Becke, A. D. J. Chem. Phys. 1993, 98, 5648-5652. (c) Lee, C.; Yang, W.; Parr, R. G. Phys. Rev. B, 1988, 37, 785-789.

(S35) Foresman, J. B.; Frisch, A. Exploring Chemistry with Electronic Structure Methods: second ed.; Gaussian, Inc., Pittsburgh, PA, USA, 1996; Chapters 6-7.

(S36) Torshin, I. Y.; Weber, I. T.; Harrison, R. W. Protein Eng. 2002, 15, 359-363.

(S37) (a) Wieczorek, R.; Dannenberg, J. J. J. Am. Chem. Soc. 2004, 126, 14198-14205. (b) Topol, I. A.; Burt, S. K.; Deretey, E.; Tang, T.-H.; Perczel, A.; Rashin, A.; Csizmadia, I. G. J. Am. Chem. Soc. 2001, 123, 6054-6060.

(S38) Aurora, R.; Rose, G. D. Protein Sci. 1998, 7, 21-38.

(S39) Milner-White, E. J. J. Mol. Biol. 1988, 199, 503-511.

(S40) For CH- $\pi$ interactions, see: (a) Brandl, M.; Weiss, M. S., Jabs, A.; Sühnel, J.; Hilgenfeld, R. J. Mol. Biol. 2001, 307, 357-377. (b) Re, S.; Nagase, S. Chem. Commun. 2004, 658-659.

(S41) (a) Morokuma, K. Bull. Korean Chem. Soc. 2003, 24, 797-801. (b) Torrent, M.; Vreven, T.; Musaev, D. G.; Morokuma, K.; Farkas, Ö.; Schlegel, H. B. J. Am. Chem. Soc. 2002, 124, 192-193. (c) Contreras-Torres, F. F.; Basiuk, V. A. J. Phys. Chem. A 2006, 110, 7431-7440.

(S42) For simulations of Ala-based peptide helices through semiempirical MO, DFT, and ONIOM methods, see: (a) Wieczorek, R.; Dannenberg, J. J. J. Am. Chem. Soc. 2003, 125, 8124 -8129. (b) Wieczorek, R.; Dannenberg, J. J. J. Am. Chem. Soc. 2005, 127, 17216-17223. See also ref S37a. 
(S43) At the high layer, both the $\mathrm{C}^{\alpha}$ termini were treated as the " $\mathrm{CH}_{3}$ ", according to the default settings in Gaussian 03, which also provided scaling factors for the $\mathrm{C}-\mathrm{H}$ lengths. ${ }^{\mathrm{S} 33}$ For a similar treatment, see refs S37a,S42b. In the initial modeling, the layers were set on the Gauss View. $^{\text {S44 }}$

(S44) GaussView, Version 3.09, Dennington II, R.; Keith, T.; Millam, J.; Eppinnett, K.; Hovell, W. L.; Gilliland, R. Semichem, Inc., Shawnee Mission, KS, 2003.

(S45) Estimation of the helix content was obtained according to ref S45a: (a) Shepherd, N. E.; Abbenante, G.; Fairlie, D. P. Angew. Chem. Int. Ed. 2004, 43, 2687-2690. In ref S45a, the ideal $[\theta]_{222}$ and $k$ parameters are based on refs S45b,c: (b) Luo, P.; Baldwin, R. L. Biochemistry 1997, 36, 8413-8421. (c) Chen, Y.-H.; Yang, J. T.; Chau, K. H. Biochemistry 1974, 13, 3350-3359. Here the ideal $[\theta]_{222}{ }^{\mathrm{S} 45 \mathrm{a}}$ corresponds to the value $(-44000)^{\mathrm{S} 45 \mathrm{~b}}$ at $0{ }^{\circ} \mathrm{C}$ without the correction of chain terminal, while the $k(2.6)^{\mathrm{S} 45 \mathrm{a}}$ is slightly rounded off from the original value (2.57). ${ }^{\mathrm{S} 45 \mathrm{c}}$

(S46) The ideal $[\theta]_{222}$ showed some temperature dependence. ${ }^{\mathrm{S} 45 \mathrm{~b}}$ If assuming ca. $20{ }^{\circ} \mathrm{C}$ in the measurement, the ideal $[\theta]_{222}$ would be given as $-39000 .{ }^{\mathrm{S}}{ }^{\mathrm{b}} \mathrm{b}$ Based on the ideal $[\theta]_{222}$ at 20 ${ }^{\circ} \mathrm{C}^{\mathrm{S} 45 \mathrm{~b}}$ and the original $k^{\mathrm{S} 45 \mathrm{c}}$, the helix content corresponding to "81\%" increased to ca. $92 \%$.

(S47) Sukumar, M.; Gierasch, L. M. Fold Des. 1997, 2, 211-222.

(S48) The heterochiral type I helix of $m=20$ involves both $6 \rightarrow 1$ and $5 \rightarrow 2$ hydrogen bonds, in which the preceding Ala sequence adopts an essentially $\alpha$-helix. In $m=4$ and 5, such short Ala segment might not stabilize an $\alpha$-helical conformation overwhelmingly. ${ }^{\text {S37 }}$ This might be the origin of instability in the heterochiral helix of $m=4$ and 5.

(S49) For the PCM method, see: (a) Mennucci, B.; Cancès, E.; Tomasi, J. J. Phys. Chem. B 1997, 101, 10506-10517. (b) Cossi, M.; Scalmani, G.; Rega, N.; Barone, V. J. Chem. Phys. 2002, 117, 43-54. (c) Cancès, E.; Mennucci, B.; Tomasi, J. J. Chem. Phys. 1997, 107, 3032-3041. (d) Mennucci, B.; Tomasi, J. J. Chem. Phys. 1997, 106, 5151-5158. (e) Cossi, M.; Barone, V.; Mennucci, B.; Tomasi, J. Chem. Phys. Lett. 1998, 286, 253-260. These and full references are given in ref $\mathrm{S} 33 \mathrm{~b}$.

(S50) The single-point DFT was performed for the types I and II helices (shown in Figure 3) at the PCM method in Gaussian 03: for the important parameters, "pcm" for "scrf", "TABS"=298.15, "ALPHA"=1.2, and "TSNUM"=70. ${ }^{\mathrm{S} 3-\mathrm{S} 35, \mathrm{~S} 49}$ Under these conditions, tesserae were generated in numbers of $6 \times 10^{3}-7 \times 10^{3}$. Hydrogen was treated as united atom at the "UA0" model. ${ }^{\mathrm{S} 33, \mathrm{~S} 35, \mathrm{~S} 49}$ Solvent parameters including dielectric constant were set to the default values in Gaussian $03 .^{\text {S33 }}$

(S51) For dielectric constant in Figure S17, see refs S33,S51a,b. (a) Riddick, J. A., Bunger, W. B. Organic Solvents: Physical Properties and Methods of Purification. third ed., Wiley-Interscience, Inc., New York, USA, 1970; Chapter 3. For that of 2,2,2-trifluoroethanol, 
see: (b) Hong, D.-P., Hoshino, M., Kuboi, R., Goto, Y. J. Am. Chem. Soc. 1999, 121, 8427-8433. For the $\mathrm{E}_{\mathrm{N}}^{\mathrm{T}}$ as another polarity parameter, see: (c) Reichardt, C. Solvents and Solvent Effects in Organic Chemistry, third edition; Chapter 7 \& Appendix, Wiley-VCH, Weinheim, Germany, 2003. (d) Hill, D. J.; Moore, J. S. Proc. Natl. Acad. Sci. U.S.A. 2002, 99, 5053-5057. For elegant examples of $\mathrm{E}_{\mathrm{N}}{ }^{\mathrm{T}}$-depending conformational transition in artificial helical molecules, see ref S51d.

(S52) For the dipole moment of $\alpha$-helix, see: Wada, A. Adv. Biophys. 1976, 9, 1-63.

(S53) (a) Green, M. M.; Reidy, M. P.; Johnson, R. J.; Darling, G.; O'Leary, D. J.; Willson, G. J. Am. Chem. Soc. 1989, 111, 6452-6454. (b) Green, M. M.; Garetz, B. A.; Munoz, B.; Chang, H.; Hoke, S.; Cooks, R. G. J. Am. Chem. Soc. 1995, 117, 4181-4182. (c) Nonokawa, R.; Yashima, E. J. Am. Chem. Soc. 2003, 125, 1278-1283. For chiral effects in unique molecular systems, see also: (d) Cornelissen, J. J. L. M.; Rowan, A. E.; Nolte, R. J. M.; Sommerdijk, N. A. J. M. Chem. Rev. 2001, 101, 4039-4070. (e) van Gestel, J.; Palmans, A. R. A.; Titulaer, B.; Vekemans, J. A. J. M.; Meijer, E. W. J. Am. Chem. Soc. 2005, 127, 5490-5494. (f) Tian, G.; Lu, Y.; Novak, B. M. J. Am. Chem. Soc. 2004, 126, 4082-4083. (g) Kozlov, I. A.; Orgel, L. E.; Nielsen, P. E. Angew. Chem., Int. Ed. 2000, 39, 4292-4295. (h) Tabei, J.; Shiotsuki, M.; Sato, T.; Sanda, F.; Masuda, T. Chem.-Eur. J. 2005, 11, 3591-3598. 